\title{
Antitumor Activity of Monoterpenes Found in Essential Oils
}

\author{
Marianna Vieira Sobral, ${ }^{1,2}$ Aline Lira Xavier, ${ }^{2}$ \\ Tamires Cardoso Lima, ${ }^{3}$ and Damião Pergentino de Sousa ${ }^{1,2,3}$ \\ ${ }^{1}$ Departamento de Ciências Farmacêuticas, Universidade Federal da Paraíba, 58051-970 João Pessoa, PB, Brazil \\ ${ }^{2}$ Programa de Pós-Graduação em Produtos Naturais e Sintéticos Bioativos, Universidade Federal da Paraíba, \\ Caixa Postal 5009, 58015-970 João Pessoa, PB, Brazil \\ ${ }^{3}$ Departamento de Farmácia, Universidade Federal de Sergipe, 49100-000 São Cristóvão, SE, Brazil
}

Correspondence should be addressed to Damião Pergentino de Sousa; damiao_desousa@yahoo.com.br

Received 11 April 2014; Revised 16 June 2014; Accepted 17 June 2014; Published 14 October 2014

Academic Editor: Chantal Pichon

Copyright (C) 2014 Marianna Vieira Sobral et al. This is an open access article distributed under the Creative Commons Attribution License, which permits unrestricted use, distribution, and reproduction in any medium, provided the original work is properly cited.

Cancer is a complex genetic disease that is a major public health problem worldwide, accounting for about 7 million deaths each year. Many anticancer drugs currently used clinically have been isolated from plant species or are based on such substances. Accumulating data has revealed anticancer activity in plant-derived monoterpenes. In this review the antitumor activity of 37 monoterpenes found in essential oils is discussed. Chemical structures, experimental models, and mechanisms of action for bioactive substances are presented.

\section{Introduction}

Cancer is a complex genetic disease that comprises specific hallmarks. They include sustaining proliferative signaling, evading growth suppressors, resisting cell death, enabling replicative immortality, inducing angiogenesis, and activating invasion and metastasis, apart from reprogramming of energy metabolism and evading immune destruction [1]. According to the World Health Organization (WHO), the overall impact of cancer has increased by more than the double in the last 30 years. It is estimated that in 2008 there were roughly 12 million new cancer cases and seven million deaths worldwide. Future projections indicate that cancer mortality will continue to rise, reaching 11.4 million in 2030 [2]. The study of natural products has been the single most successful strategy for the discovery of new medicines used in anticancer therapy, and more than two thirds of the drugs used in cancer treatment come directly from natural products or are developed using knowledge gained from the activity of their ingredients $[3,4]$.

In these recent years, a large number of studies have documented the efficacy of essential oils and their chemical constituents as source of new bioactive natural products [5], including against cancer [6, 7]. For example, Piaru and collaborators [8] investigated the cytotoxicity of the essential oils from Myristica fragrans and Morinda citrifolia. The results showed that the $M$. fragrans essential oil exhibited greater cytotoxic activity than the $M$. citrifolia oil, possibly due to the presence of some potential anticancer substances such as limonene, terpinen-4-ol, eugenol, and myristicin. In another study, Ferraz and collaborators [9] revealed the cytotoxic effect of leaf essential oil of Lippia gracilis Schauer and its constituents (thymol, $p$-cymene, $\gamma$-terpinene, and myrcene). Interestingly, Maggi and collaborators [10] investigated the antiproliferative activity of essential oil from Vepris macrophylla. This oil demonstrated a strong cytotoxic effect, which may be attributed by the presence of specific components such as the monoterpenes citral, citronellol, and myrcene. Furthermore, Nikolić and collaborators [11] investigated the antitumor activity of Thymus serpyllum, $T$. algeriensis, and T. vulgaris essential oils on growth of four human tumor cells. The specie T. serpyllum was the most potent in all tested cell lines and contains thymol as its major constituent, a phenolic compound known in the literature 
for its antiproliterative activity [12]. Therefore, the essential oils and chemical constituents are natural products with high pharmacological potential against various types of tumors.

Cancer is a major cause of death worldwide, ranked behind only cardiovascular disease. Considering that monoterpenes are common in many plant species and are used in cosmetic and pharmaceutical preparations, as well as the food industry, it is important to review the pharmacological potential of monoterpenes with anticancer activity.

The present study was carried out based on the literature review of monoterpenes from essential oils with antitumor activity. Chemical structures and names of bioactive compounds are provided. The monoterpenes presented in this review were selected with reference to effects shown in specific experimental models for evaluation of antitumor activity and/or by complementary studies aimed to elucidate mechanisms of action Table 1 . The selection of essential oils constituents in the database was related to various terms, including essential oils and monoterpenes as well as names of representative compounds of these chemical groups refining with antitumor activity, cytotoxic activity, and cytotoxicity. The search was performed in the scientific literature databases and Chemical Abstracts in September 2013.

1.1. Linalyl Acetate, Alpha-Terpineol, and Camphor. Linalyl acetate, alpha-terpineol, and camphor in association linalyl acetate, alpha-terpineol, and camphor caused inhibition of the growth of the human colon cancer cell lines (HCT-116 p53+/+ and p53-/-) and were inactive on FHs74Int normal human intestinal cell lines [13]. Alpha-terpineol showed significant cytotoxicity against Hep G2, a hepatocellular carcinomic human cell line; HeLa, an epithelioid carcinomic cell line; MOLT-4, a human lymphoblastic leukemia T cell line; K-562, a human chronic myelogenous leukemia cell line; and CTVR-1, an early B cell line from the bone marrow cells of a patient with acute myeloid leukemia [14]. Different officinal plants of Lebanon, among them Satureja montana, have shown cytotoxic activity against human erythroleukemic K562 cells. Its major constituent was the alpha-terpineol which demonstrated important cytotoxicity on the same cell line. Yet, this essential oil and alpha-terpineol induced erythroid differentiation of K562 cells [15]. Hassan and collaborators [16] suggested that alpha-terpineol inhibits the growth of tumor cells through a mechanism that involves inhibition of the NF- $\kappa$ B pathway.

1.2. Alloocimene. Okamura and collaborators [17] evaluated the cytotoxicity of 12 monoterpenes. The acyclic monoterpene alloocimene showed significant cytotoxic activity; its $50 \%$ inhibitory concentration $\left(\mathrm{IC}_{50}\right)$ was the highest of 12 , for mouse P388 leukemia cell among others.

1.3. Menthol. Menthol was cytotoxic for murine leukemia WEHI-3 cells in a concentration-dependent manner. The in vivo activity on WEHI-3 cells was also examined [18]. In SNU-5 cells, menthol induced cytotoxicity by inhibiting the expression of topoisomerases I, II alpha, and II beta and promoting the expression of NF- $\kappa \mathrm{B}$ [19]. This compound also enhances the antiproliferative activity of $1 \alpha, 25$-dihydroxyvitamin D3 in LNCaP cells [20]. Wang and collaborators [21] showed that menthol inhibited the proliferation and motility of prostate cancer DU145 cells. Li and collaborators [22] demonstrated that menthol induced cell death via the TRPM8 channel in a human bladder cancer cell line. Okamoto and collaborators [23] also studied the role of menthol in the blockade of TRPM8 activity and found that it reduced the invasion potential of oral squamous carcinoma cell lines.

1.4. Beta-Dolabrin. Beta-dolabrin presented in vitro cytotoxic effects against Ehrlich's ascites carcinoma and KATO-III human stomach cancer cell line [24].

1.5. Alpha- and Gamma-Thujaplicin. Alpha-thujaplicin inhibited cell growth of Ehrlich's ascites carcinoma and KATO-III human stomach cancer [25]. Gama-thujaplicin also showed strong cytotoxic effects against KATO-III and Ehrlich's ascites carcinoma at $0.32 \mu \mathrm{m} / \mathrm{mL}$, with $85 \%$ and $91 \%$ inhibition of cell growth, respectively [24].

1.6. Borneol. The cytotoxicity of borneol and its DNAdamaging effects were studied in malignant HepG2 hepatoma cells, malignant Caco- 2 colon cells, and nonmalignant human VH10 fibroblasts. Borneol showed cytotoxicity in all cell lines and did not cause DNA strand breaks at the concentrations studied. With respect to DNA-protective effects, borneol protected HepG2 and VH10 cells, but not Caco- 2 cells, against $\mathrm{H}_{2} \mathrm{O}_{2}$-induced DNA damage [26]. Su and collaborators [27] demonstrated that borneol potentiates selenocystineinduced apoptosis in human hepatocellular carcinoma cells by enhancement of cellular uptake and activation of ROSmediated DNA damage.

1.7. Ascaridole. Ascaridole exerts cytotoxic activity against different tumor cell lines (CCRF-CEM, HL60, and MDAMB-231) [28]. Bezerra and collaborators [29] investigated the cytotoxicity and antitumor activity of ascaridole and in HL-60 and HCT-8 cells lines found $\mathrm{IC}_{50}$ values of 6.3 and $18.4 \mu \mathrm{g} / \mathrm{mL}$, respectively. Results from in vivo studies using sarcoma 180 as a tumor model demonstrated inhibition rates of $33.9 \%$ at $10 \mathrm{mg} / \mathrm{kg}$ and $33.3 \%$ at $20 \mathrm{mg} / \mathrm{kg}$.

1.8. Carvacrol. Carvacrol produced significant cytotoxic activity against mouse leukemia P388 [30] and Hep-2 [31]. Horvathova and collaborators $[32,33]$ found that carvacrol exerted cytotoxic effects in K562, HepG2, and colonic Caco2 cells and significantly reduced the level of DNA damage induced in these cells by the strong oxidant $\mathrm{H}_{2} \mathrm{O}_{2}$. The cytotoxic and DNA-protective effects of carvacrol were also demonstrated by Slamenova and collaborators [34]. Carvacrol displays cytotoxicity against B16-F10 melanoma cells and this cytotoxicity is reduced by the addition of vitamin $\mathrm{C}$ and vitamin E. In the P815 mastocytoma cell line, carvacrol showed a dose-dependent cytotoxic effect, but when tested on normal human peripheral blood mononuclear cells, it showed a proliferative effect rather than a cytotoxic one [31]. 


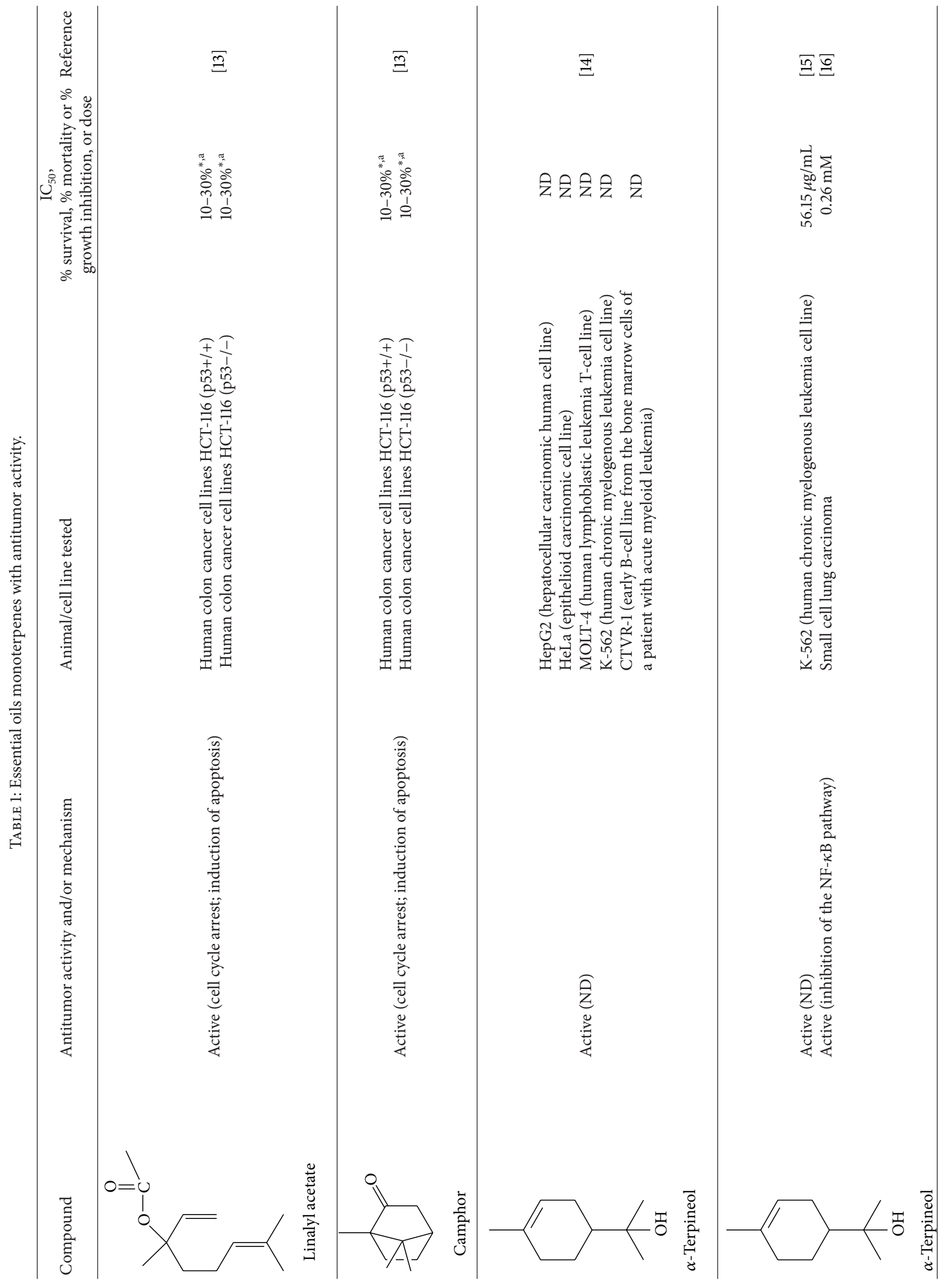




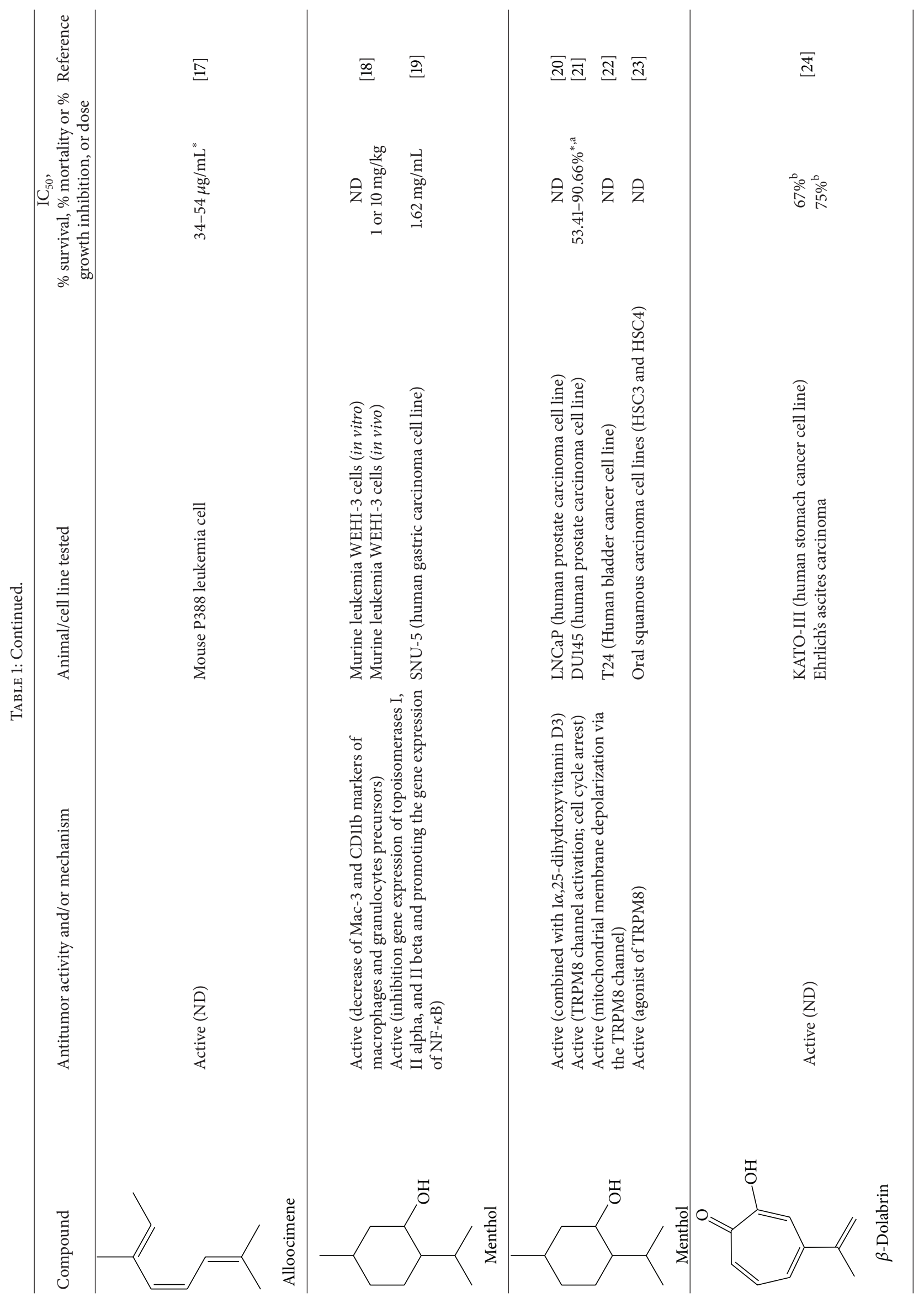




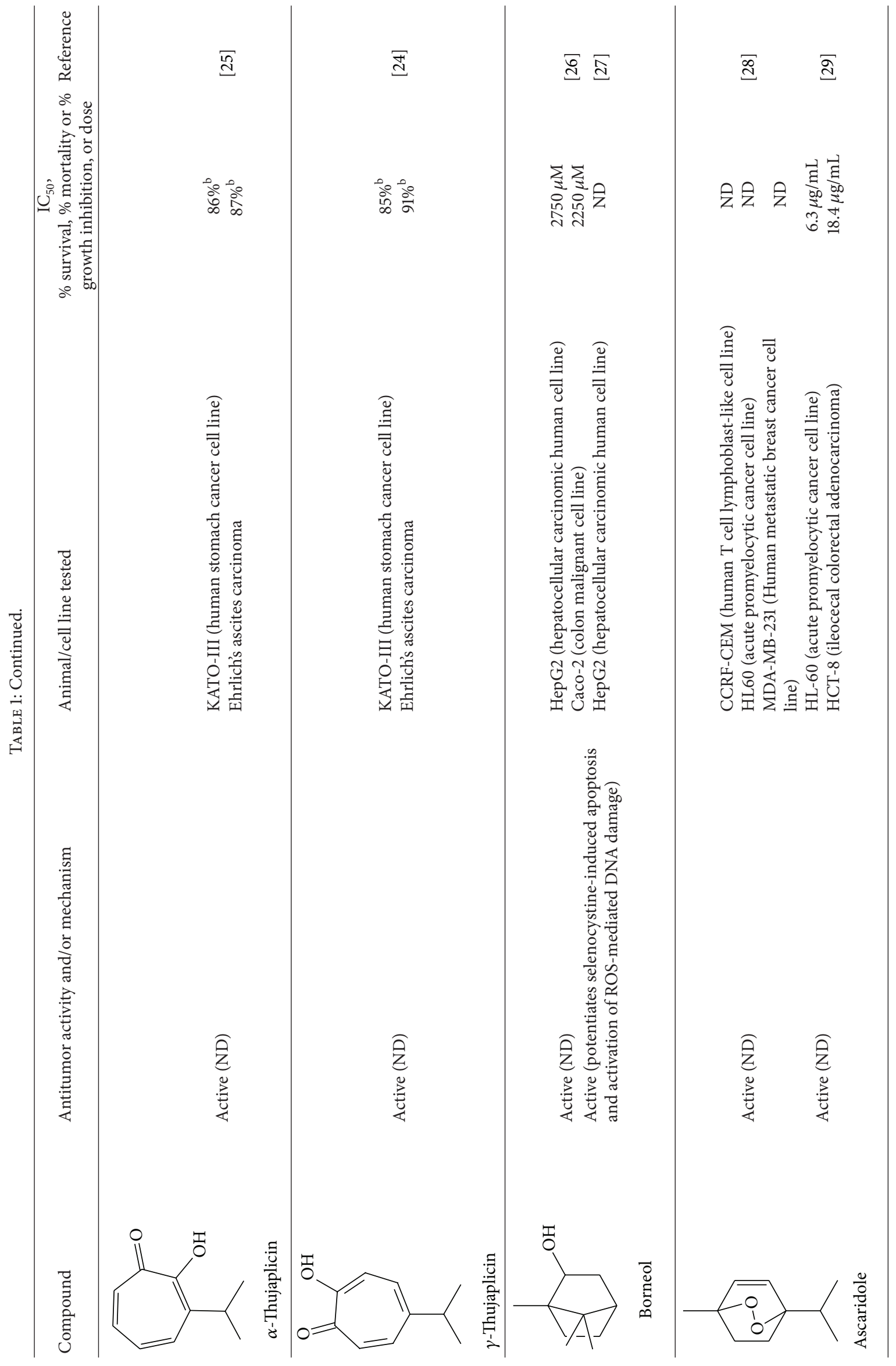




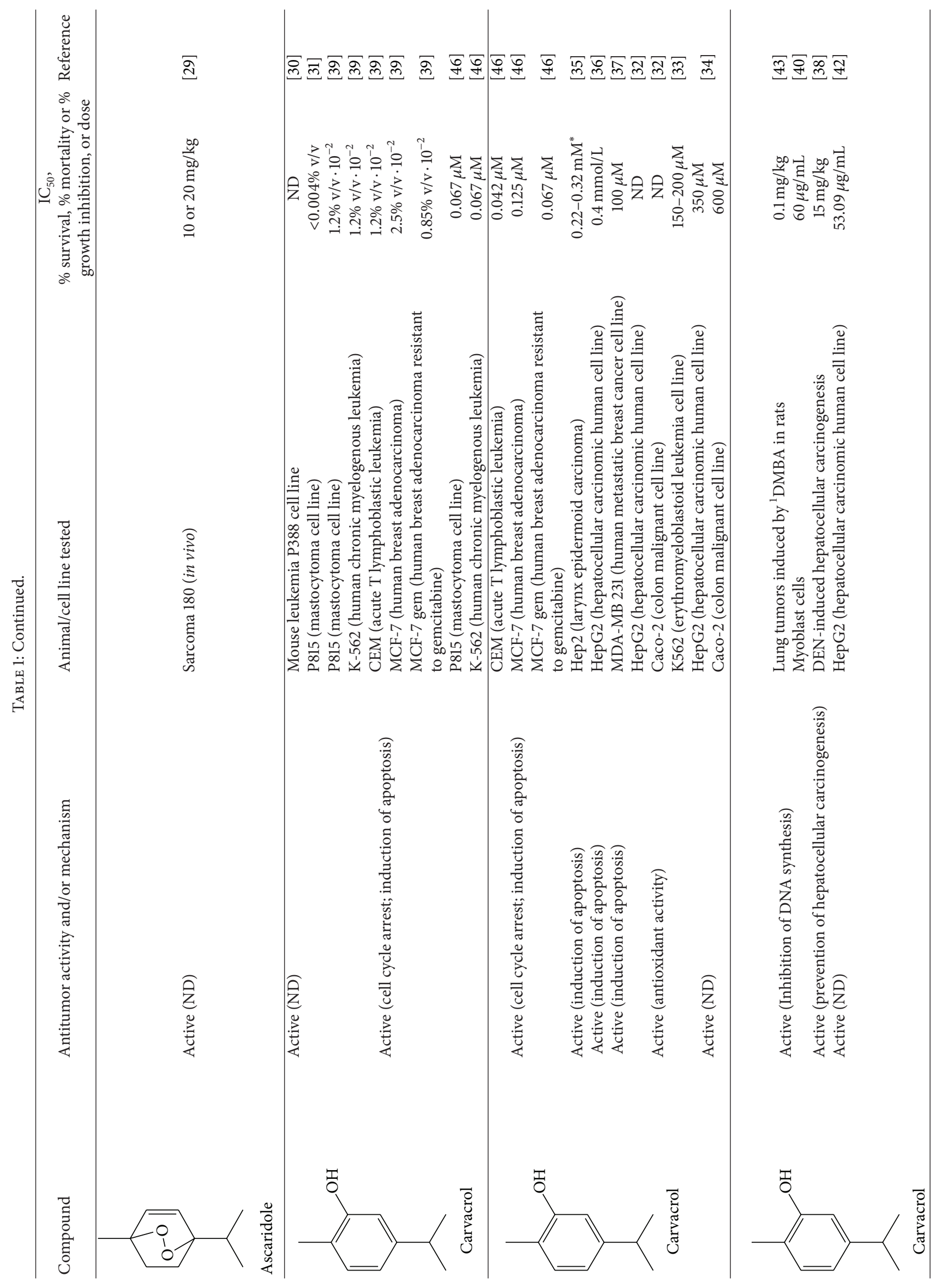




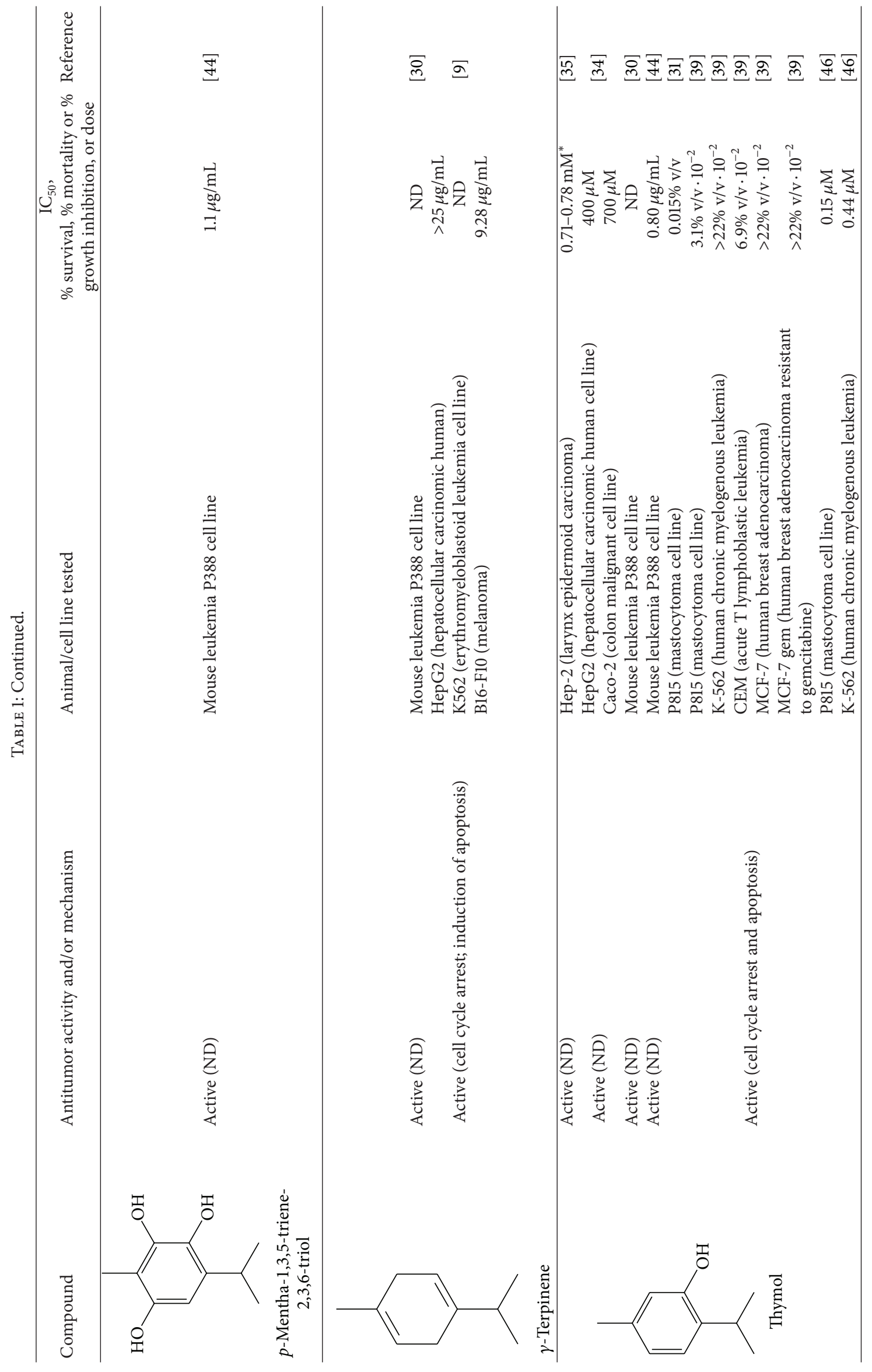




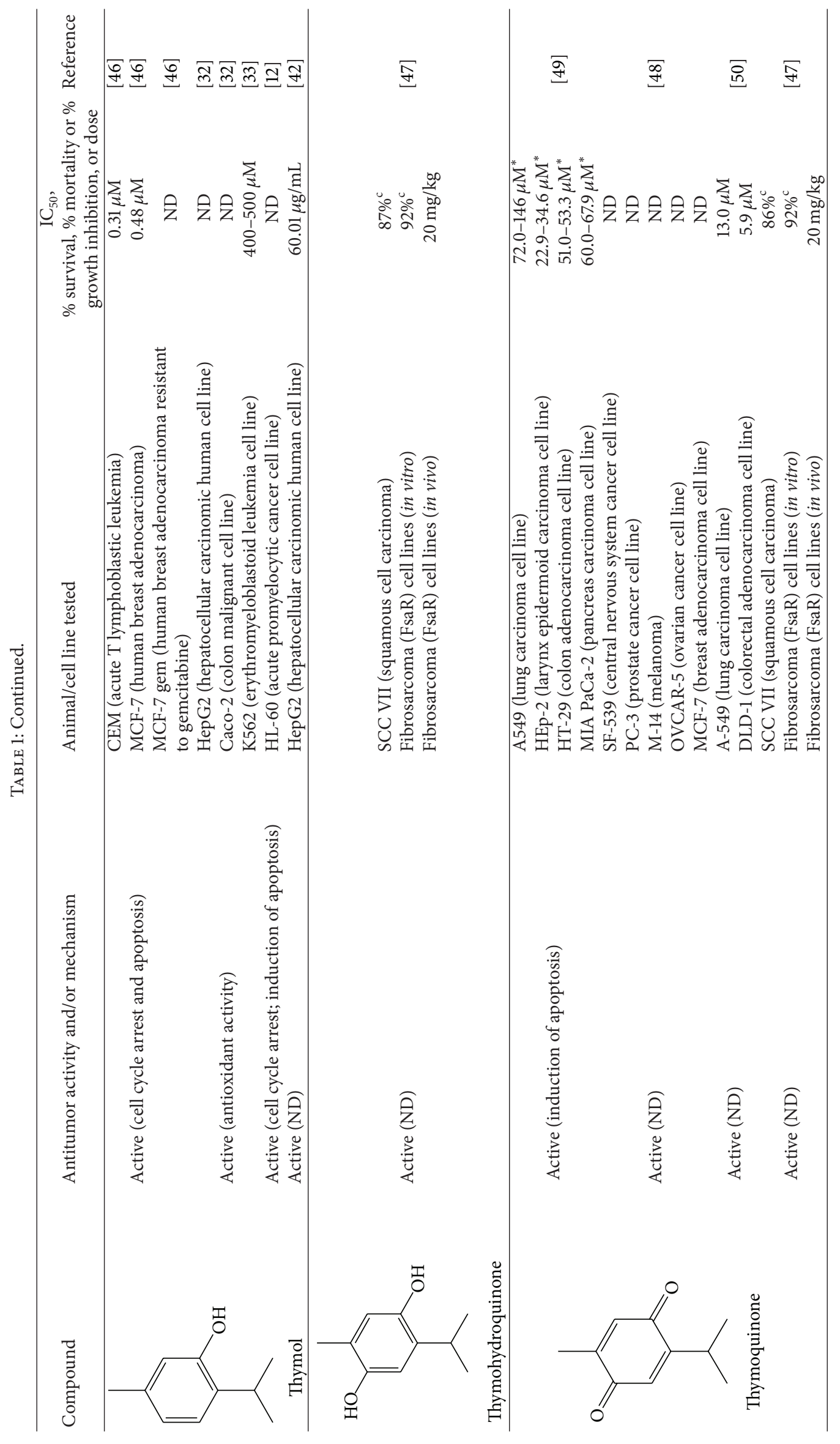




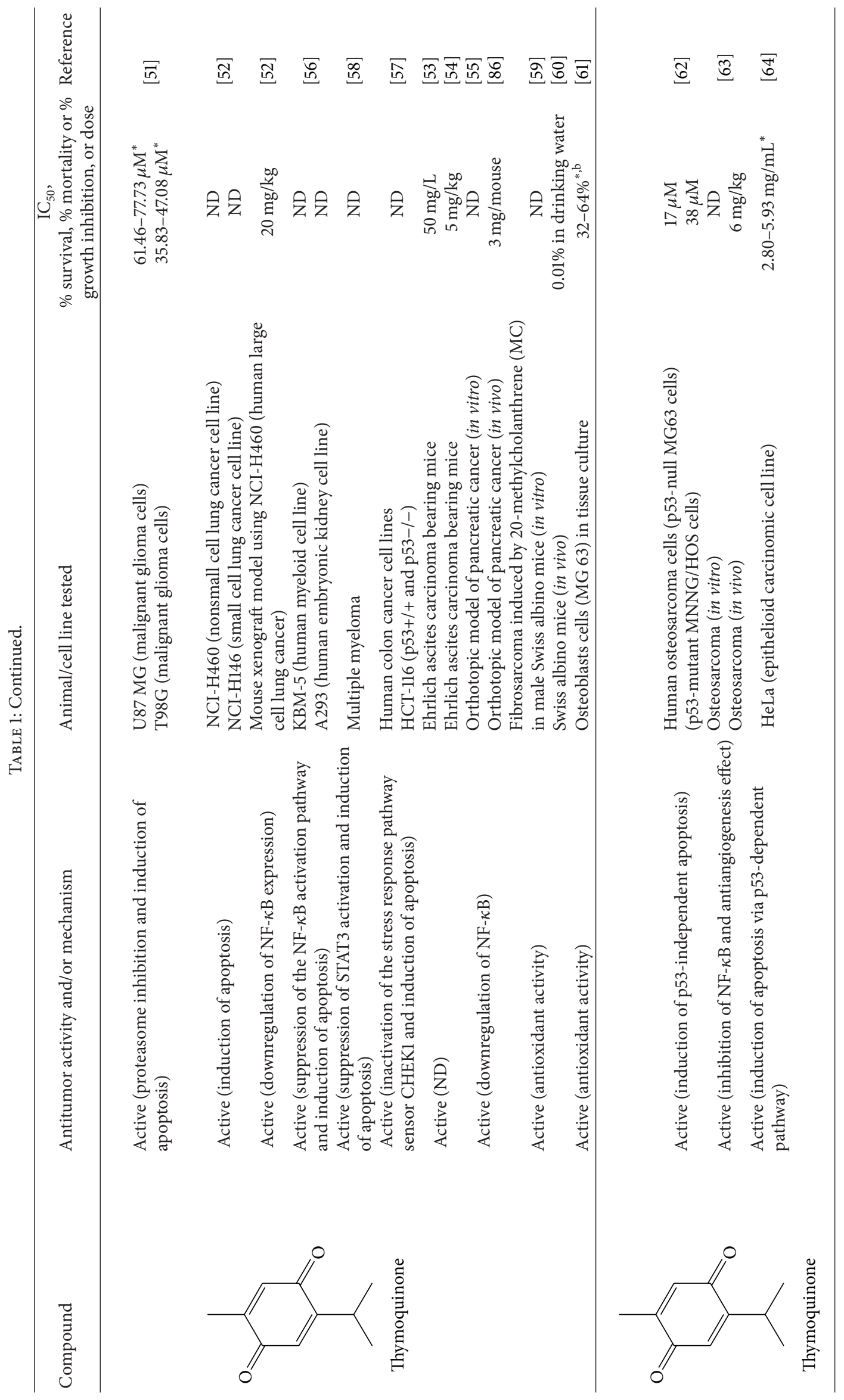




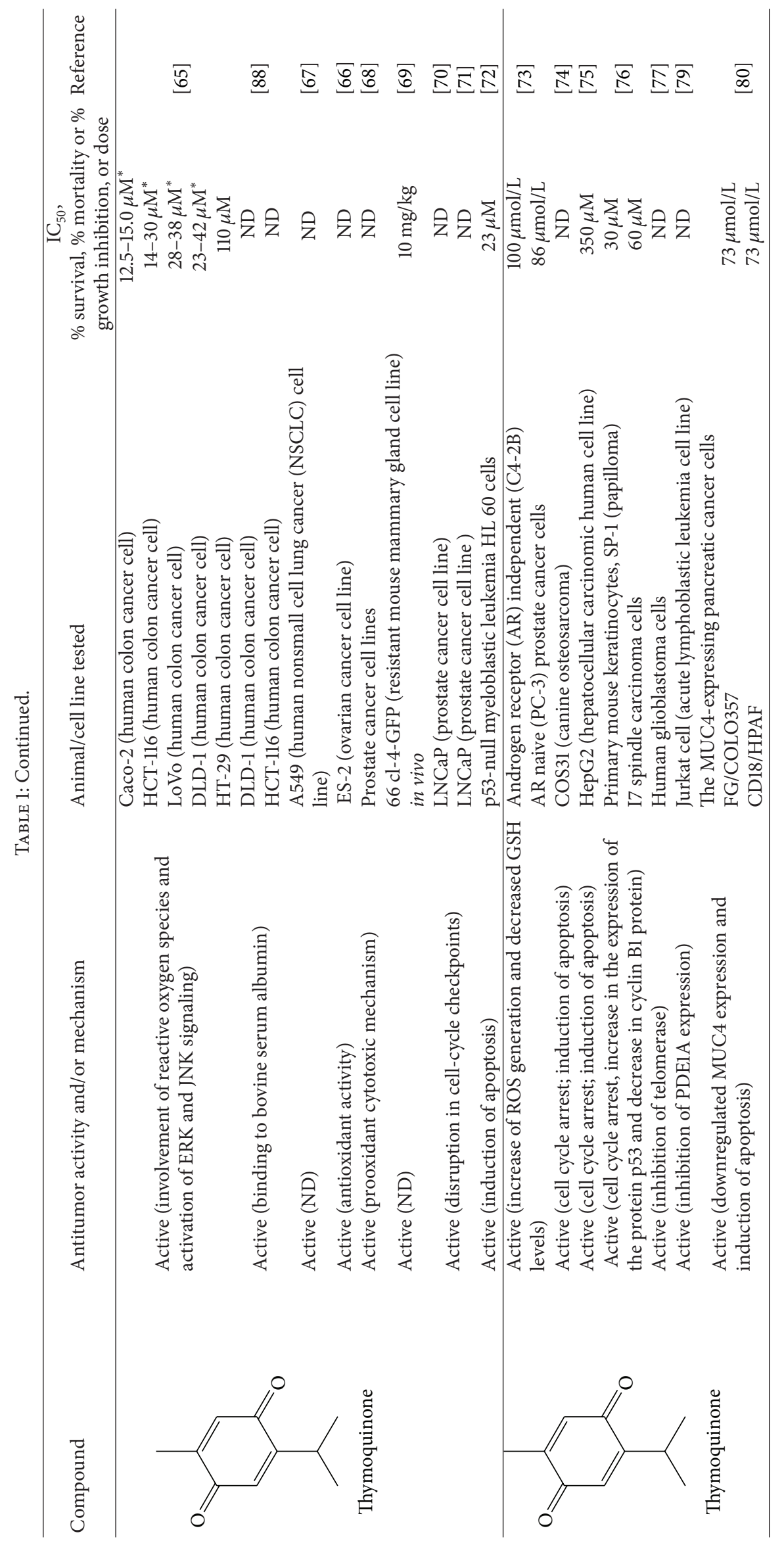




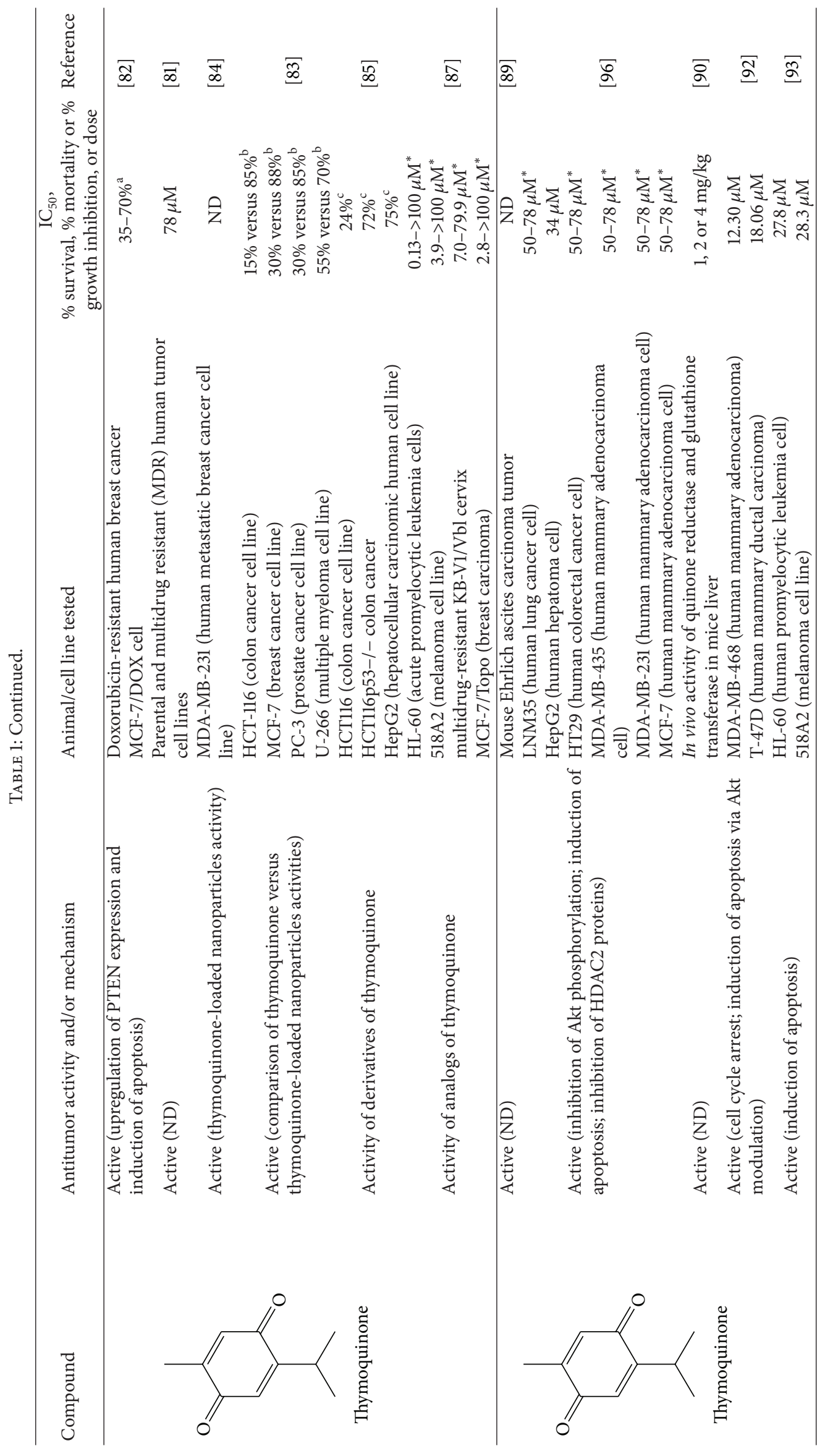




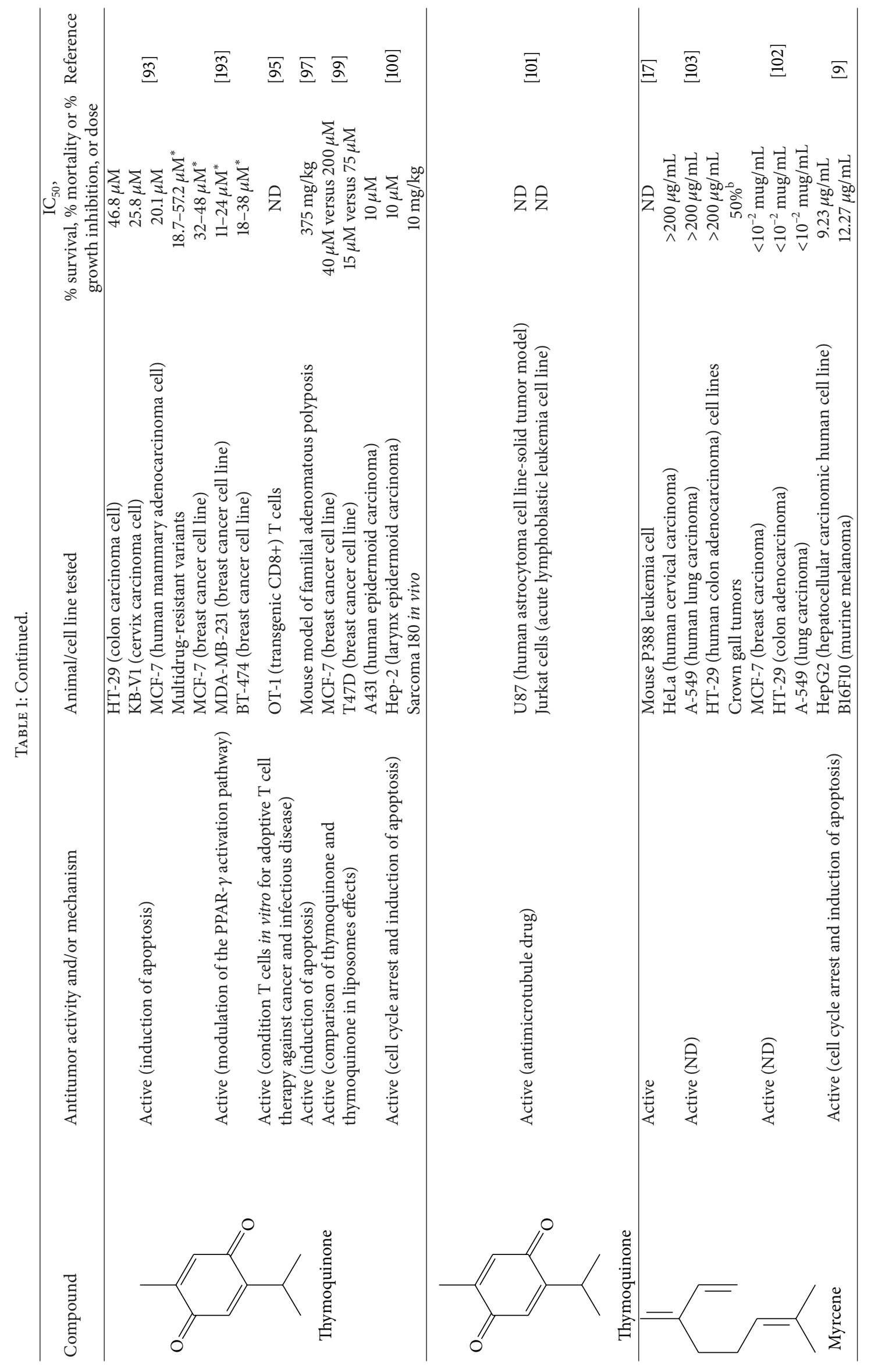




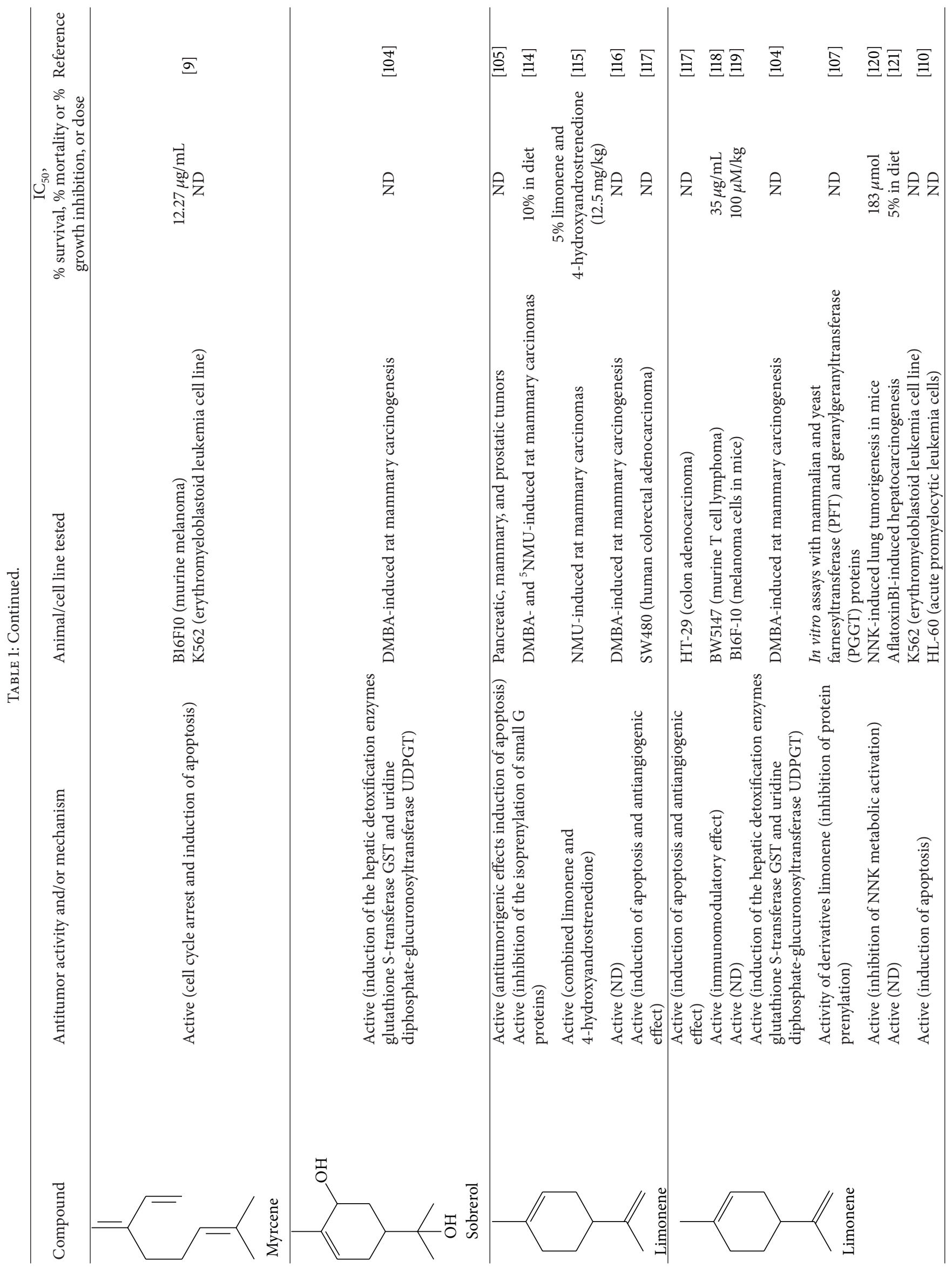




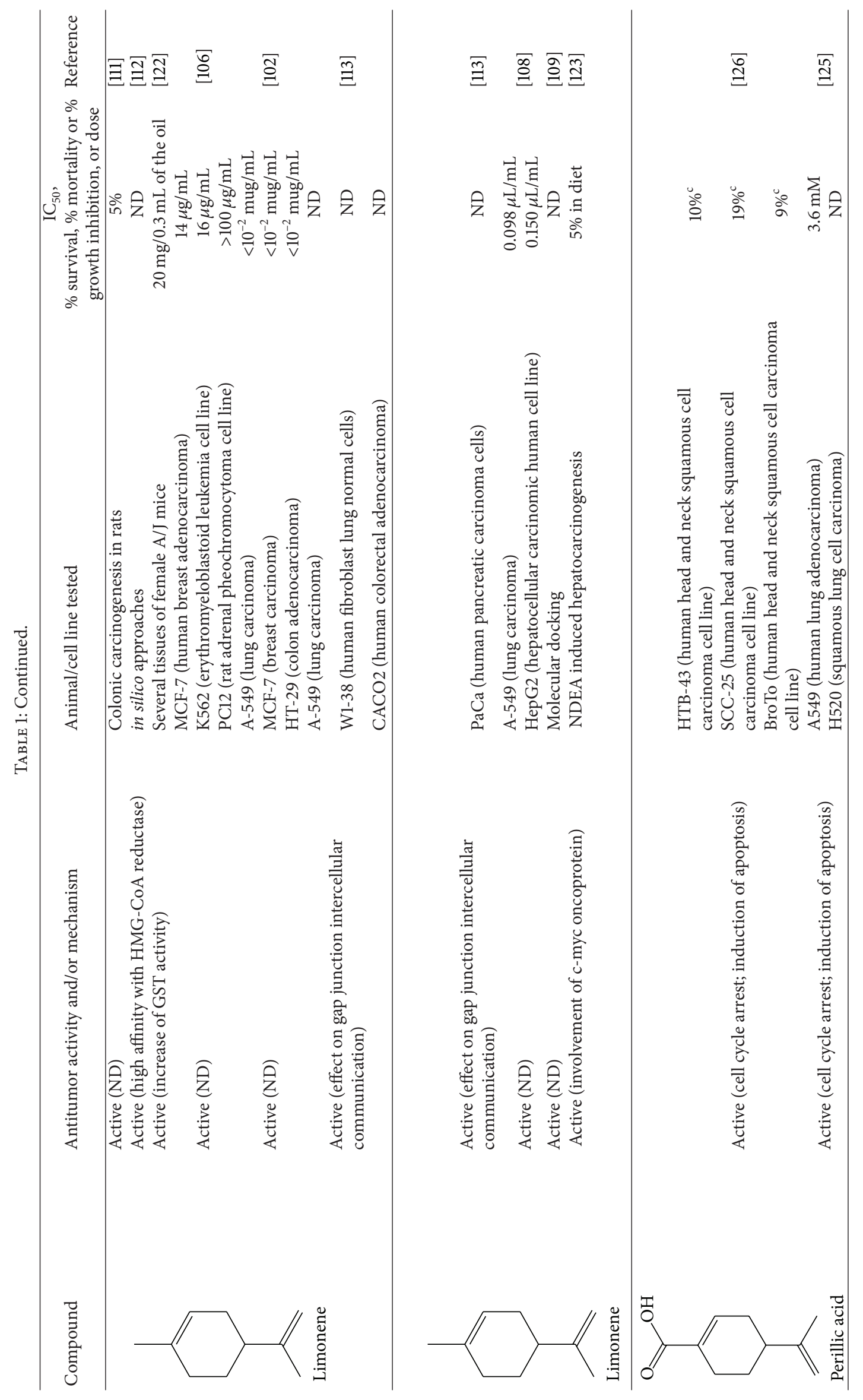




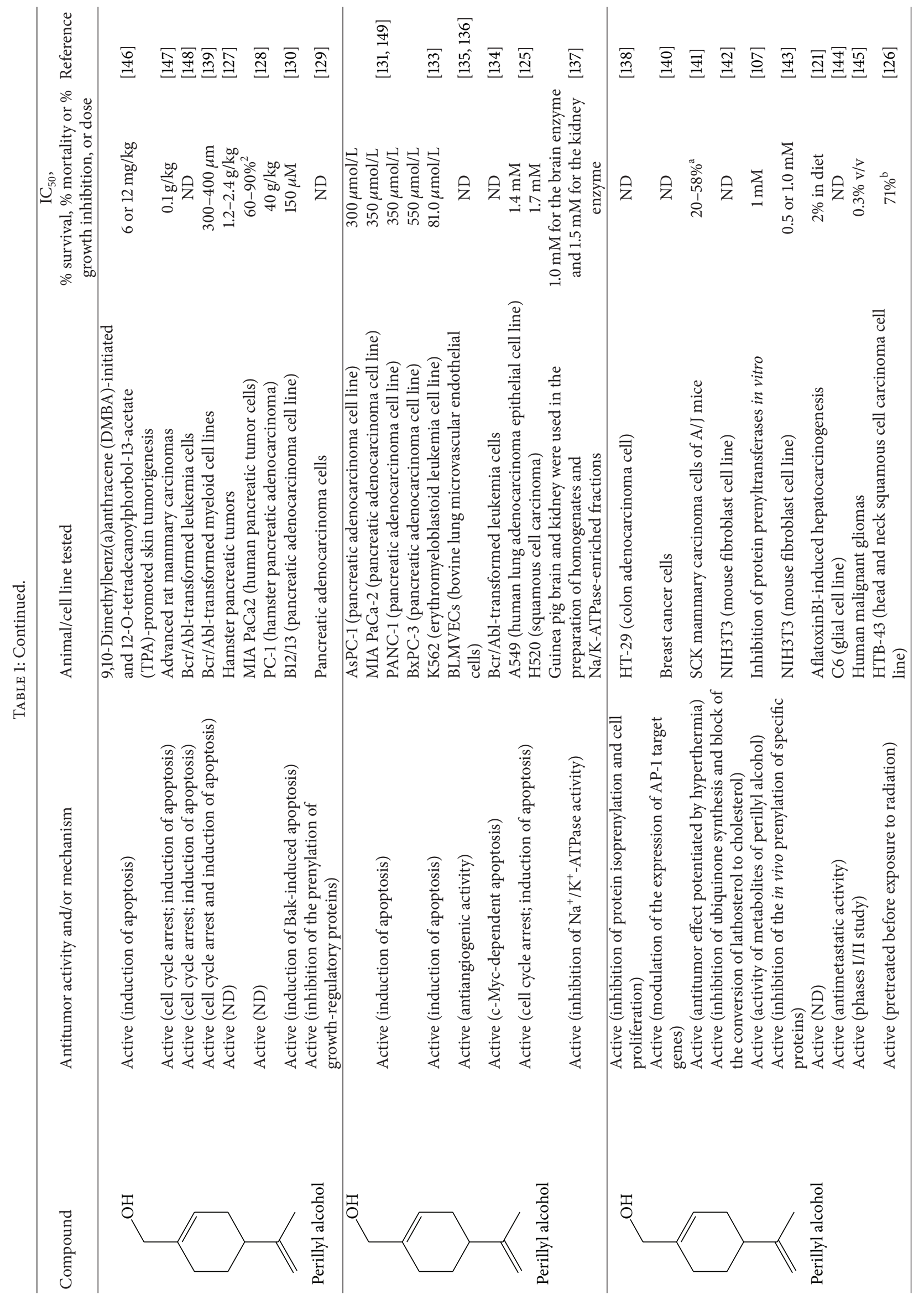




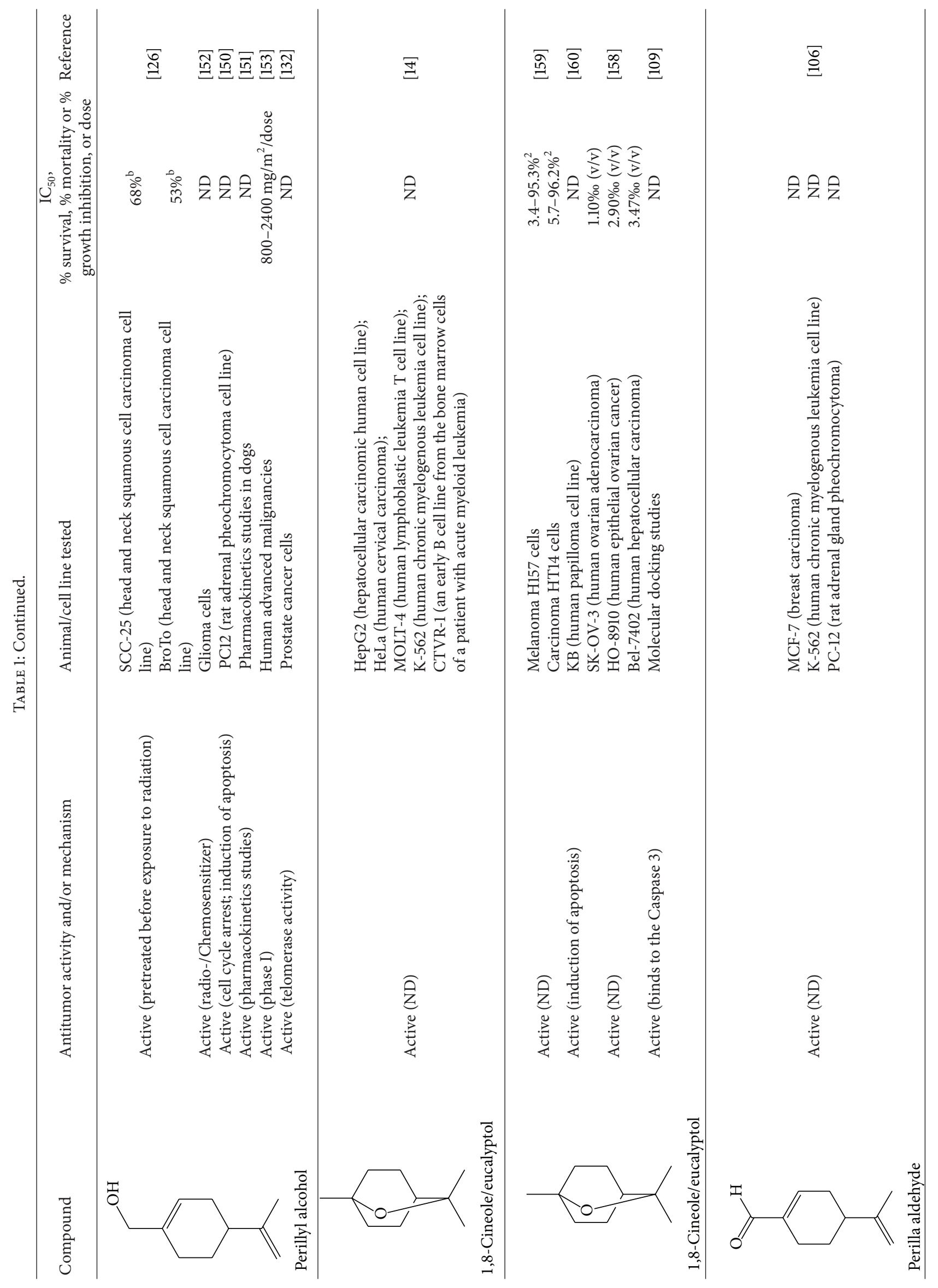




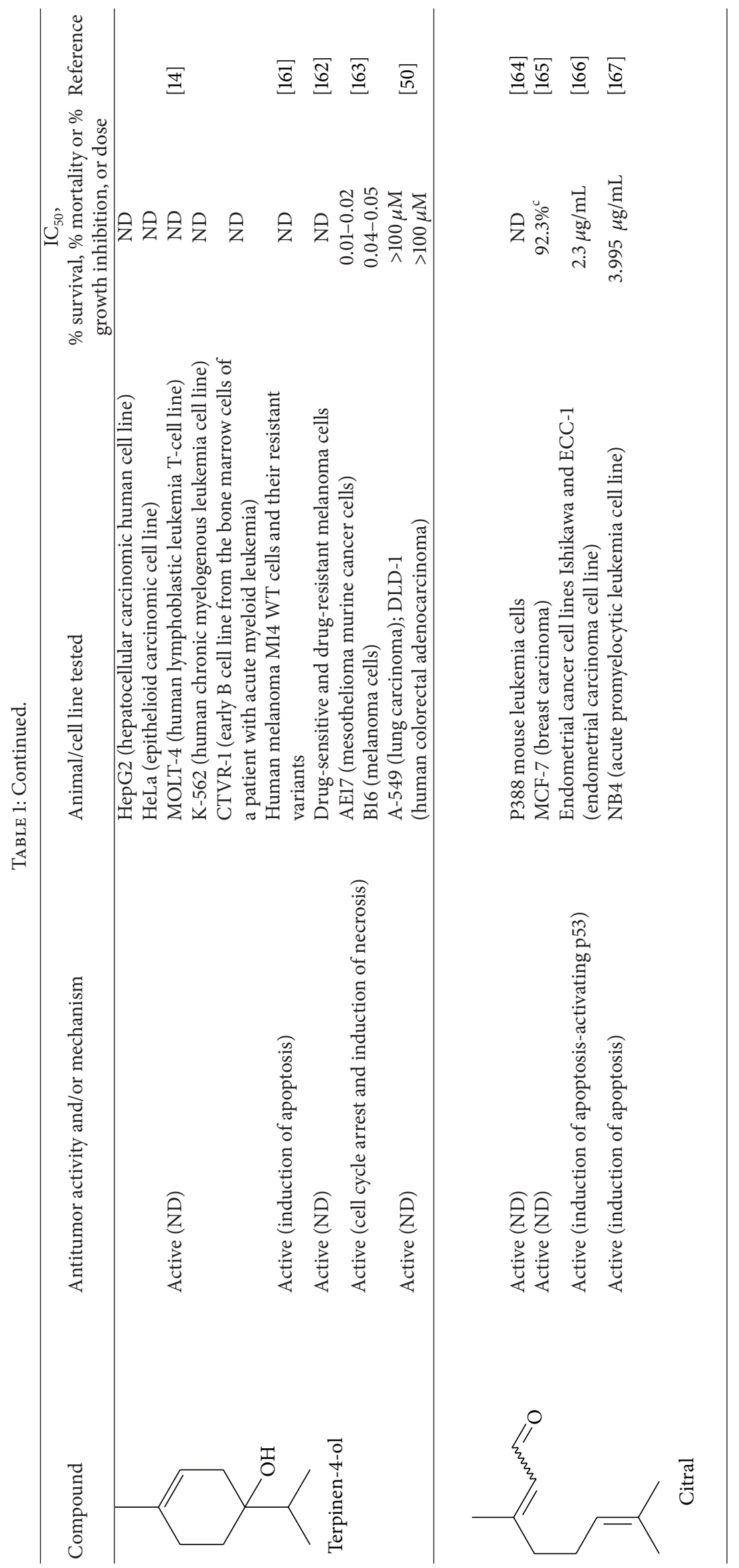




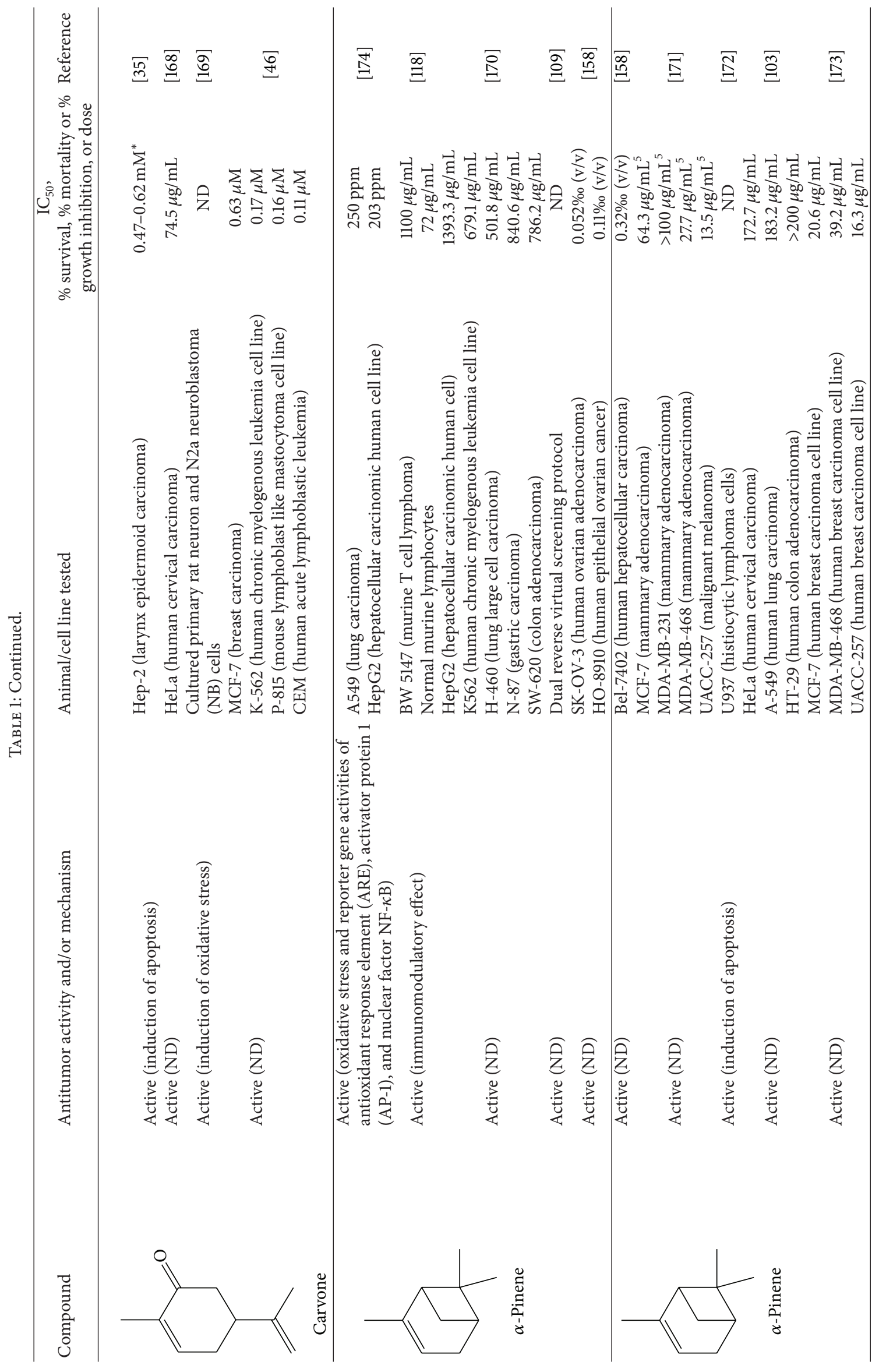




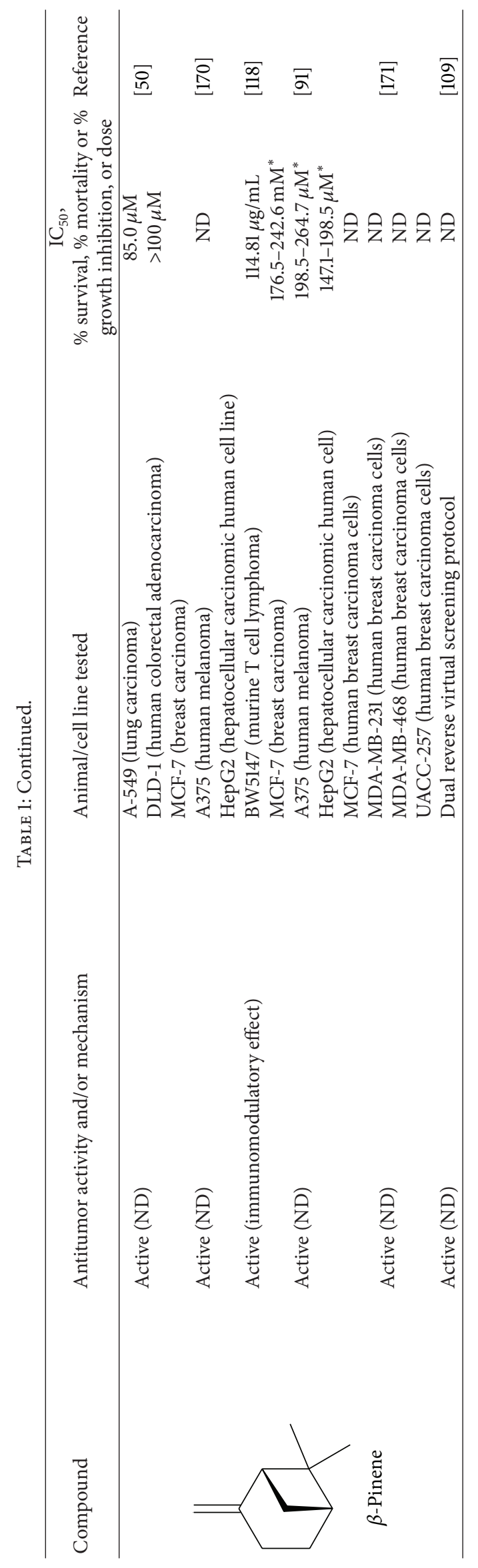




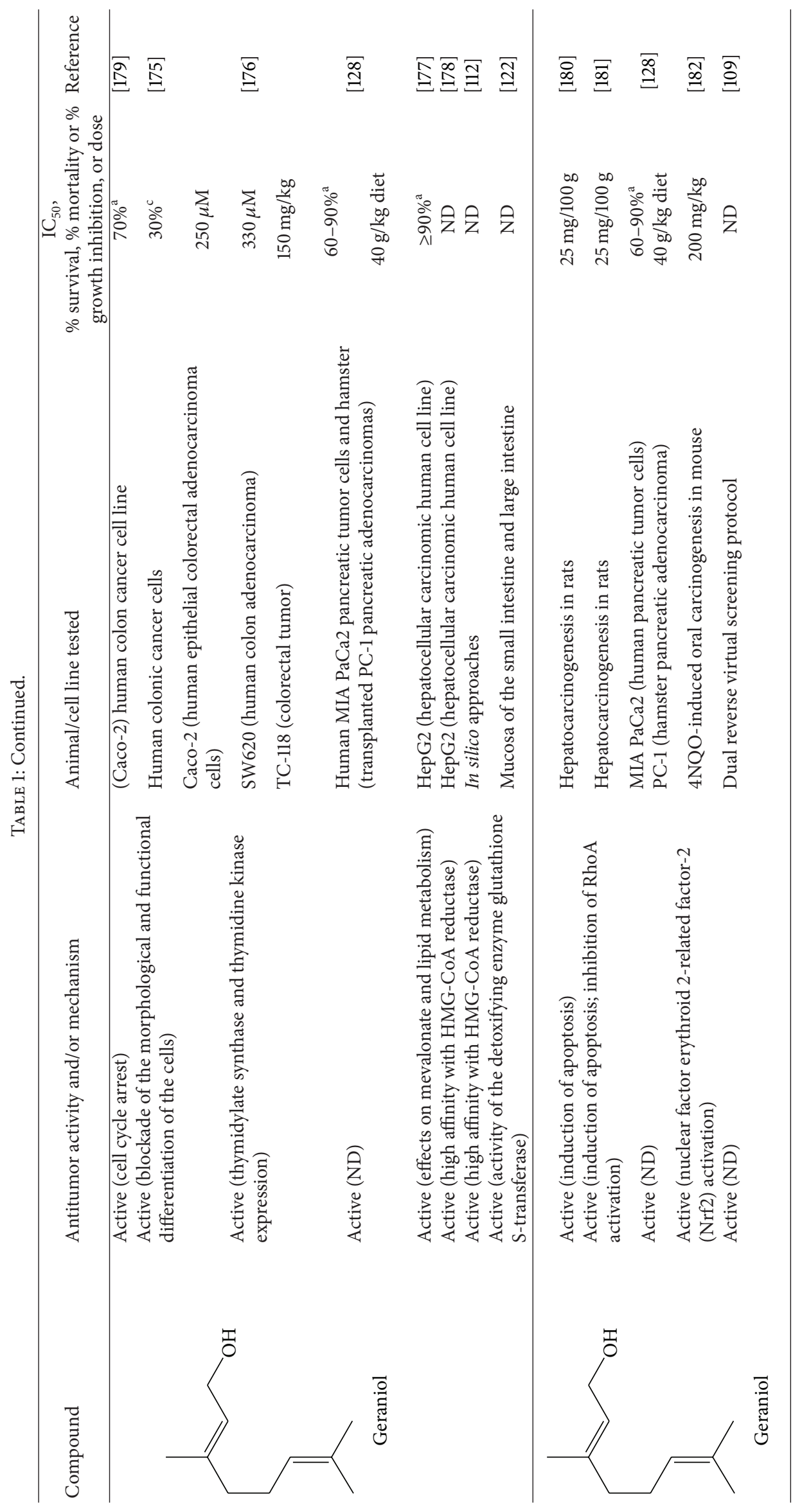




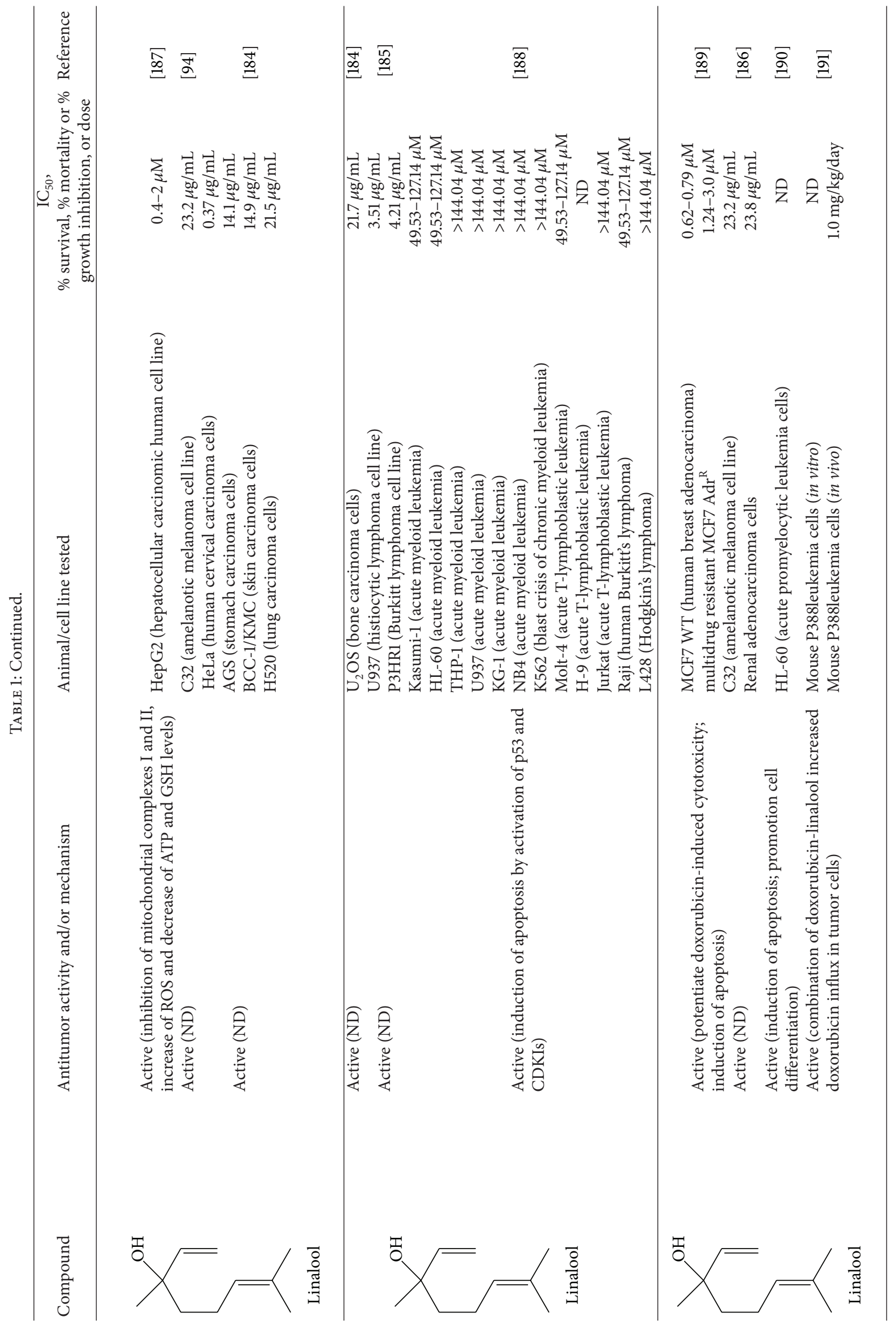




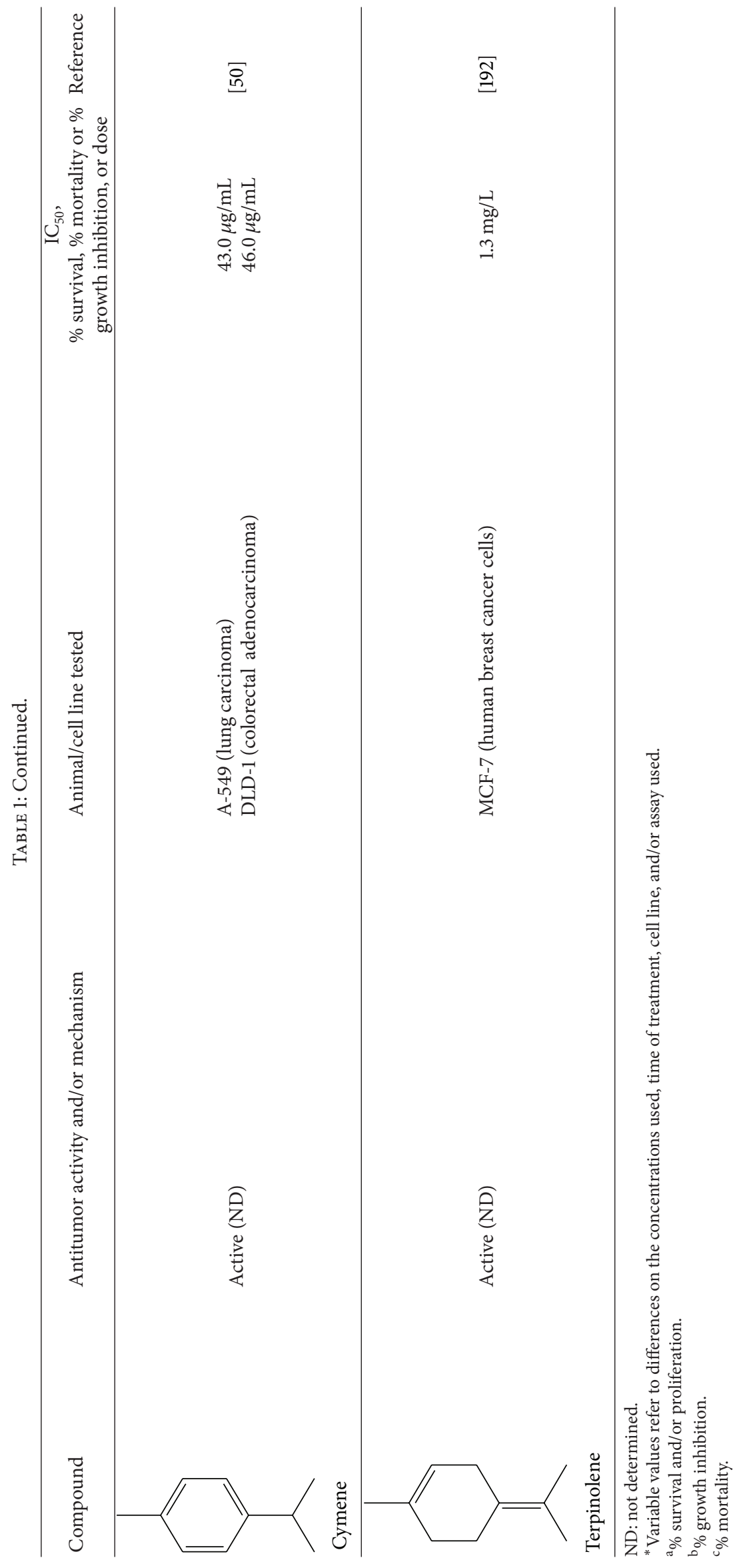


In the work of Stammati and collaborators [35], the authors compared the cytotoxic effects and molecular mechanisms of 5 monoterpenes: carvacrol, thymol, carveol, carvone, and isopulegol. Yin and collaborators [36] have proved the involvement of apoptosis in the cytotoxic effects of carvacrol on HepG2 cells. Arunasree [37] investigated the mechanism of carvacrol-induced cell death in MDA-MB 231 human metastatic breast cancer cells and demonstrated that this compound induced apoptosis in a dose-dependent manner [37]; the mechanism of action of carvacrol may in fact be related to its antioxidant activity and not associated with a DNA-damaging effect. Jayakumar and collaborators [38] demonstrated that carvacrol protects the antioxidant system in DEN-induced hepatocellular carcinogenesis. Carvacrol induced cell cycle arrest at $S$ phase and induced apoptosis in P815 tumor cell line [39]. Zeytinoglu and collaborators [40] found that carvacrol inhibited growth of myoblast cells even after activation of a mutated N-ras oncogene. The essential oil of Origanum onites and carvacrol, its major constituent, showed strongly inhibition of the mutagenicity induced by 4-nitro-o-phenylenediamine and 2-aminofluorene using Salmonella typhimurium strains TA98 and TA100. These results indicate that the essential oil and carvacrol have pharmacological importance for the prevention of cancer because of its significant antimutagenicity effect [41]. The carcinogenesis-reducing potential of carvacrol was demonstrated by Ozkan and Erdogan [42]. Carvacrol was also tested against lung tumors induced by dimethylbenz $[\alpha]$ anthracene (DMBA) in rats in vivo and it was found to have strong antitumor activity at $0.1 \mathrm{mg} / \mathrm{kg}$ i.p. Although the mechanism of action of antitumor activity of carvacrol was not investigated in this study, evidence for an inhibitory effect on angiogenesis was observed [43].

1.9. p-Mentha-1,3,5-triene-2,3,6-triol. From the methanol extract of Majorana syriaca, Hirobe and collaborators [44] isolated the $p$-mentha-1,3,5-triene-2,3,6-triol. The screening for cytotoxicity on P388 cells showed significant activity for its monoterpene.

1.10. Terpinene. Terpinene showed significant evidence for antioxidant activity and cytotoxic activity against mouse leukemia P388 cells [31]. Ferraz and collaborators [9] evaluated the cytotoxicity of the essential oil of Lippia gracilis and its constituents against HepG2, K562, and B16-F10 tumor cell lines. Terpinene showed cytotoxic activity selectively for B16F10 cells.

1.11. Thymol. Thymol presented cytotoxic effect against Hep2 cells [35], P815 mastocytoma cells [31], HepG2 human hepatoma cells, Caco-2 human colonic cells, and V79 hamster lung cells [34]. Thymol showed antioxidant activity and cytotoxic activity against the mouse leukemia P388 cell line $[30,44]$. Jayakumar and collaborators $[38,42]$ demonstrated that thymol is cytotoxic against HepG2 human hepatoma cells, colonic Caco- 2 cells, and K562 cells, via a mechanism that may be related to antioxidant activity and not associated with a DNA-damaging effect. The effects of thymol on murine
B16-F10 melanoma cells were tested by Paramasivam and collaborators [45], and thymol exhibited cytotoxicity with an $\mathrm{IC}_{50}$ value of $88.5 \mu \mathrm{g} / \mathrm{mL}$. Thymol cytotoxicity was reduced by addition of vitamin $\mathrm{C}$ and vitamin $\mathrm{E}$. Radical scavengers (butylated hydroxytoluene and butylated hydroxyanisole) were able to significantly recover cell viability. Yin and collaborators [36] demonstrated that thymol induced cell cycle arrest at G0/G1 phase. Deb and collaborators [12] demonstrated that thymol induced apoptosis in HL-60 cells via caspase-dependent and caspase-independent pathways. Oskan and collaborators [42] demonstrated the antioxidant activity and carcinogenesis-reducing potential of thymol. In the work of Jaafari and collaborators [46], the authors compared the cytotoxic effects and molecular mechanisms of 5 monoterpenes: carvacrol, thymol, carveol, carvone, and isopulegol.

1.12. Thymohydroquinone. Studies have shown significant cytotoxic activity for thymohydroquinone in squamous cell carcinoma (SCC VII) and fibrosarcoma (FsaR) cell lines. This activity was dose dependent and more effective against tumor cells than L929 fibroblasts. Thymohydroquinone also showed a tumor inhibition rate of $52 \%$ in vivo [47]. On the other hand, Johnson and collaborators [48] showed that the reduction of thymoquinone to thymohydroquinone resulted in a 1.7-fold decrease in its cytotoxic potency against PC-3 tumor cells [48].

1.13. Thymoquinone. Thymoquinone possesses antiproliferative and proapoptotic activities in several cell lines [48-50]. Ivankovic and collaborators [47] showed cytotoxicity and also antitumor activity of thymoquinone. Cecarini and collaborators [51] demonstrated that thymoquinone induced timedependent selective proteasome inhibition in glioblastoma cells and isolated enzymes and suggested that this mechanism could be implicated in the induction of apoptosis in cancer cells. The activity of thymoquinone against nonsmall cell lung cancer (NSCLC) and small cell lung cancer (SCLC) cell lines, alone and in combination with cisplatin (CDDP), was evaluated by Jafri and collaborators [52]. The authors observed that thymoquinone inhibited cell proliferation, reduced cell viability, and induced apoptosis. Thymoquinone inhibited cell proliferation by nearly $90 \%$ and showed synergistic effects with cisplatin. Thymoquinone was able to induce apoptosis in NCI-H460 and NCI-H146 cell lines. In a mouse xenograft model, the combination of thymoquinone and CDDP was well tolerated and significantly reduced tumor volume and tumor weight. Badary and collaborators [53] investigated the effects of thymoquinone on cisplatin-induced nephrotoxicity in mice and rats, and results revealed that thymoquinone induced amelioration of cisplatin nephrotoxicity and potentiated its antitumor activity. This natural product is also capable of improving the therapeutic efficacy of ifosfamide by decreasing ifosfamide-induced nephrotoxicity and improving its antitumor activity [54]. The chemosensitizing effect of thymoquinone on conventional chemotherapeutic agents was also demonstrated by Banerjee and collaborators. 
In vitro studies demonstrated that preexposure of cells to thymoquinone followed by gemcitabine or oxaliplatin resulted in greater growth inhibition compared with gemcitabine or oxaliplatin used alone. The mechanism involves downregulation of nuclear factor- $\kappa \mathrm{B}(\mathrm{NF}-\kappa \mathrm{B}), \mathrm{Bcl}-2$ family genes, and NF- $\kappa \mathrm{B}$-dependent antiapoptotic genes [55]. Thymoquinone downregulated NF- $\kappa \mathrm{B}$ expression, which may explain its various cellular activities [52]. Sethi and collaborators [56] evaluated the involvement of suppression of the NF- $\kappa \mathrm{B}$ activation pathway in apoptosis induced by thymoquinone. Gali-Muhtasib and collaborators [57] demonstrated that thymoquinone triggered inactivation of the stress response pathway sensor CHEK1 and contributed to apoptosis in colorectal cancer cells. In human, multiple myeloma cells thymoquinone inhibited proliferation, induced apoptosis, and induced chemosensitization, through suppression of the signal transducer and activator of transcription 3 (STAT3) activation pathway [58]. Badary and collaborators [59, 60] demonstrated a powerful chemopreventive activity for thymoquinone against MC-induced fibrosarcoma tumors, suggesting that its mechanisms of action include antioxidant activity and interference with DNA synthesis, coupled with enhancement of detoxification processes $[59,60]$. Barron and collaborators [61] examined the effects of thymoquinone and selenium (an endogenous antioxidant) on the proliferation of MG 63 osteoblasts cells in tissue culture and found that the combined use of these substances may be an effective treatment option against human osteosarcoma cells. The utilization of thymoquinone in the treatment of human osteosarcoma is also suggested by Roepke and collaborators [62], who showed that it induced p53-independent apoptosis, which is important because loss of p53 function is frequently observed in osteosarcoma patients. In contrast, Peng and collaborators [63] demonstrated antitumor and antiangiogenesis effects of thymoquinone on osteosarcoma through the NF- $\kappa \mathrm{B}$ pathway. Yazan and collaborators [64] reported that thymoquinone was cytotoxic to HeLa cells in a dose- and time-dependent manner and induced apoptosis via a p53-dependent pathway. Reactive oxygen species were also involved in mediating thymoquinone-induced apoptosis in a panel of human colon cancer cells (Caco-2, HCT-116, LoVo, DLD-1, and HT-29) through activation of ERK and JNK signaling [65]. WilsonSimpson and collaborators [66] evaluated the participation of thymoquinone in the treatment of ES-2 ovarian tumor cells, and Farah and collaborators [67] evaluated the effects of antioxidants and thymoquinone on the cellular metabolism of A549 cells. Zubair and collaborators [68] demonstrated that redox cycling of endogenous copper by thymoquinone led to ROS-mediated DNA breakage and cell death. Talib and Abu Khader [69] studied the combinatorial effects of thymoquinone on the anticancer activity and hepatotoxicity of the prodrug CB 1954. Furthermore, findings from Richards and collaborators $[70,71]$ revealed that sustained delivery of antioxidants with thymoquinone may be a means of treating prostate cancer safely and effectively. In HEp-2 human laryngeal carcinoma cells, GSH depletion and caspase 3 activation mediated thymoquinone-induced apoptosis [49]. Caspase 3 activation (as well as caspase 8 and caspase 9) is related to thymoquinone-induced apoptosis in p53-null HL-60 cancer cells [72]. In prostate cancer cells, thymoquinone induced GSH depletion and increased ROS generation [73]. Shoieb and collaborators [74] demonstrated that the mechanism of action of thymoquinone on cancer cells involves apoptosis and cell cycle arrest. Apoptosis and cell cycle arrest were also evidenced in the studies of Hassan and collaborators [75] in the HepG2 hepatocellular carcinoma cell line and in the studies of Gali-Muhtasib and collaborators [76] in primary mouse keratinocytes, papilloma (SP-1), and spindle (I7) carcinoma cells. Gurung and collaborators [77] suggested that in glioblastoma cells thymoquinone induced DNA damage, telomere attrition through telomerase inhibition, and cell death. More recently, Paramasivam and collaborators [78] showed that thymoquinone produced cytotoxic effects on Neuro-2a mouse neuroblastoma cells through caspase 3 activation, with downregulation of XIAP. Abusnina and collaborators [79] demonstrated that thymoquinone induces acute lymphoblastic leukemia cell apoptosis. Thymoquinone also has potential as a novel therapeutic agent against pancreatic cancer. Torres and collaborators [80] demonstrated that thymoquinone downregulated MUC4 expression in pancreatic cancer cells and induced apoptosis by two different pathways. The activity of thymoquinone against multidrug resistant (MDR) human tumor cell lines was also evaluated by Worthen and collaborators [81]. el-SA and collaborators [82] show that thymoquinone upregulated PTEN expression and induced apoptosis in doxorubicin-resistant human breast cancer cells. This study suggested that thymoquinone may not be an MDR substrate and that radical generation may not be critical to its cytotoxic activity [81]. Ravindram and collaborators [83] demonstrated that encapsulation of thymoquinone into nanoparticles enhanced its antiproliferative and chemosensitizing effects. The same type of study was conducted by Ganea and collaborators [84]. Wirries and collaborators [85] reported that structural modifications may contribute to the further clinical studies with thymoquinone. Banerjee and collaborators [86] and Effenberger and collaborators [87] also analyzed thymoquinone analogs with potential cytotoxicity against cancer cells. El-Najjar and collaborators [88] showed that bovine serum albumin played a protective role against thymoquinone-induced cell death. AlShabanah and collaborators [89] demonstrated that thymoquinone protected against doxorubicin-induced cardiotoxicity without compromising its antitumor activity. Nagi and Almakki [90] investigated a potential role for thymoquinone in protection against chemical carcinogenesis and toxicity by inducing quinone reductase and glutathione transferase in mice liver. Thymoquinone inhibited proliferation, induced apoptosis, and chemosensitized human multiple myeloma cells through suppression of the signal transducer and activator of transcription 3 (STAT3) activation pathway [91]. Rajput and collaborators [92] showed that molecular targeting of Akt by thymoquinone promoted G1 arrest through translation inhibition of Cyclin D1 and induced apoptosis in breast cancer cells. Effenberger-Neidnicht and collaborators [93] showed that thymoquinone boosted the anticancer effects of doxorubicin in certain cancer cell. Tundis and collaborators [94] demonstrated the possible involvement of the PPAR$\gamma$ pathway in the anticancer activity of thymoquinone in 
breast cancer cells. Thymoquinone enhances survival and activity of antigen-specific CD8-positive $\mathrm{T}$ cells in vitro, a result that can be useful in the cancer therapy [95]. Exposure of cancer cells derived from lung, liver, colon, melanoma, and breast to increasing thymoquinone concentrations presented a significant inhibition of viability with an inhibition of Akt phosphorylation, DNA damage, and activation of mitochondrial proapoptotic pathways. Thymoquinone inhibited the invasive potential of various cancer cells. Moreover, thymoquinone synergizes with cisplatin to inhibit cellular viability. Tumor growth inhibition was associated with a significant increase in activated caspase 3 . In silico target identification suggested several potential targets of thymoquinone, in particular HDAC2 proteins and 15-hydroxyprostaglandin dehydrogenase [96]. Lang and collaborators [97] showed that thymoquinone interfered with polyp progression in ApcMin mice through induction of tumor-cell specific apoptosis and modulation of Wnt signaling through activation of GSK$3 \beta$. Thymoquinone also induced apoptosis in oral cancer cells through P38 $\beta$ inhibition [98]. Odeh and collaborators [99] described the encapsulation of thymoquinone into a liposome, which maintained stability and improved bioavailability, while it maintained anticancer activity. Das and collaborators [100] showed that thymoquinone and diosgenin, alone and in combination, inhibited cell proliferation and induced apoptosis in squamous cell carcinoma. Alhosin and collaborators [101] demonstrated that thymoquinone induced degradation of $\alpha$ - and $\beta$-tubulin proteins in human cancer cells without affecting their levels in normal human fibroblasts.

1.14. Myrcene. Myrcene showed significant cytotoxic effects in crown gall tumors, MCF-7 breast carcinoma, HT-29 colon adenocarcinoma [102], and other cell lines [9]. Silva and collaborators [103] investigated the cytotoxicity of myrcene against HeLa (human cervical carcinoma), A-549 (human lung carcinoma), HT-29 (human colon adenocarcinoma), and Vero (monkey kidney) cell lines as well as mouse macrophages. Okamura and collaborators [17] performed a screening of 12 monoterpenes. Among them, the acyclic monoterpene, myrcene, exhibited significant cytotoxicity against P388 leukemia cell.

1.15. Sobrerol. Sobrerol showed anticarcinogenic activity during the initiation phase of DMBA-induced carcinogenesis, which was mediated through induction of the hepatic detoxification enzymes glutathione-S-transferase and uridine diphosphoglucuronosyl transferase [104].

1.16. Limonene. Studies have demonstrated the antitumorigenic effects of limonene against pancreatic cancer and breast cancer [105]. Limonene showed antioxidant and radical scavenging activities in several model systems and cytotoxicity against MCF-7, K562, PC 12 [106], A-549, HT-29 cell lines [107], and HepG2 hepatocarcinoma cell lines [108]. Bhattacharjee and Chatterjee [109] promoted the identification of proapoptotic, anti-inflammatory, antiproliferative, antiinvasive, and potential antiangiogenic activities of limonene by employing a dual reverse virtual screening protocol. A probabilistic set of antitumor targets was generated, which can be further confirmed by in vivo and in vitro experiments. Ji and collaborators [110] demonstrated that induction of apoptosis by d-limonene was mediated by a caspasedependent mitochondrial death pathway in human leukemia cells. Furthermore, d-limonene induced apoptosis in HL-60 cells through activation of caspase-8 [111]. Pattanayak and collaborators [112] verified that limonene inhibited the activity of HMG-CoA reductase due to greater binding affinity with the receptor and thus reduced the possibility of cancer growth. Chen and collaborators [113] suggested that the anticancer activity of limonene might be related to inhibition of the membrane association of P21ras protein and increased gap junction intercellular communication. Haag and collaborators [114] demonstrated that limonene induced regression of mammary carcinomas, and when given in combination with 4-hydroxyandrostrenedione it resulted in greater rat mammary tumor regression (83.3\%) than either agent given alone [115]. Elson and collaborators [116] demonstrated that limonene reduced the average number of rat mammary carcinomas that developed in 7,12-dimethylbenz $[\alpha]$ anthracenetreated rats when the terpene was fed during the initiation or promotion/progression stages of carcinogenesis. Chidambara and collaborators [117] tested citrus volatile oil rich in d-limonene and verified that the oil induced apoptosis and acted as an antiangiogenic with a preventative effect on colon cancer. Limonene also showed a selective antiproliferative action on tumor lymphocytes [118], and it inhibited the metastatic progression of B16F-10 melanoma cells in mice [119]. Limonene had anticarcinogenic activity when fed during the initiation stage of DMBA-induced rat mammary carcinogenesis, and this mechanism was mediated through the induction of the hepatic detoxification enzymes glutathioneS-transferase and uridine diphosphoglucuronosyl transferase [104]. Gelb and collaborators [107] tested the ability of limonene to inhibit protein prenylation enzymes in vitro and found that it was a weak inhibitor of both mammalian and yeast protein farnesyltransferase (PFT) as well as protein geranylgeranyl transferase (PGGT). D-Limonene is an effective inhibitor of 4-(methylnitrosamino)-1-(3-pyridyl)-1butanone metabolic activation [120]. Elegbede and Gould [121] investigated the effects of limonene at the initiation stage of aflatoxin B1-induced hepatocarcinogenesis and found that limonene significantly inhibited aflatoxin-DNA adduct formation in hepatocytes, which suggested that limonene may have potential as a chemopreventive agent against aflatoxininduced liver cancer. D-Limonene inhibited the development of colonic aberrant crypt foci induced by azoxymethane in F344 rats, which suggested that this monoterpenoid might be a chemopreventive agent for colonic carcinogenesis in rats [111]. D-Limonene induced GST activity 2.4-3.0-fold higher than controls in the mouse liver and mucosa of the small intestine and large intestine, which suggested chemopreventive activity [122]. Parija and Ranjan [123] demonstrated the involvement of YY1 in NDEA-induced hepatocarcinogenesis and chemoprevention mediated by d-limonene. 
1.17. p-Mentha-2,8-dien-1-ol and p-Mentha-8(9)-en-1,2-diol. Zheng and collaborators [124] demonstrated the ability of $p$-mentha-2,8-dien-1-ol and $p$-mentha-8(9)-en-1,2-diol to inhibit benzo $[\alpha]$ pyrene-induced carcinogenesis in the mouse forestomach. The number of tumors per mouse was also significantly decreased by these compounds. No tumor inhibition was observed with $p$-mentha-2,8-dien-1-ol.

1.18. Perillic Acid. Yeruva and collaborators [125] demonstrated that perillic acid demonstrated dose-dependent cytotoxicity in A549 and H520 cell lines, inducing cell cycle arrest and apoptosis. Combination studies revealed that previous exposure of cells to perillic acid sensitized the cells to cisplatin and radiation in a dose-dependent manner. Samaila and collaborators [126] showed that perillic acid has potential for use as a radiosensitizer in chemoradiation therapy of head and neck cancers.

1.19. Perillyl Alcohol. Stark and collaborators [127] and Burke and collaborators [128] demonstrated that perillyl alcohol has antitumor activity against pancreatic carcinomas at nontoxic doses and may be an effective chemotherapeutic agent for human pancreatic cancer. The antitumor activity of perillyl alcohol against pancreatic cancers may stem from its ability to inhibit the prenylation of growth-regulatory proteins other than K-Ras, including H-Ras [129]. Furthermore, the antitumor activity of perillyl alcohol in pancreatic cancers may be due to preferential stimulation of Bak-induced apoptosis in malignant cells compared to normal cells [130]. Further studies to evaluate the cytotoxicity mechanisms of perillyl alcohol against pancreatic cancer cells were conducted by Lebedeva and collaborators [131]. Sundin and collaborators [132] demonstrated that the perillyl alcohol inhibited telomerase activity in prostate cancer cells. Perillyl alcohol in combination with STI571 enhances the ability of STI571 to inhibit proliferation and induce apoptosis in K562 cells [133]. In bcr/abl-transformed leukemia cells perillyl alcohol induced c-myc-dependent apoptosis [134]. In A549 and H520 cell lines, Yeruva and collaborators [125] demonstrated that perillyl alcohol presented dose-dependent cytotoxicity with cell cycle arrest and apoptosis. Elevated expression of bax, p21, and increased caspase 3 activity were evidenced. Other studies revealed that perillyl alcohol sensitized cancer cells to cisplatin and radiation in a dose-dependent manner. Perillyl alcohol attenuated in vitro angiogenesis, modulated angiogenic factor production, and inhibited cell proliferation and survival in endothelial and tumor cells [135]. Loutrati and collaborators [136] also demonstrated that perillyl alcohol, in additional to its anticancer activity, may be an effective agent in the treatment of angiogenesis-dependent diseases. Garcia and collaborators [137] demonstrated that perillyl alcohol is an $\mathrm{Na} / \mathrm{K}$-ATPase inhibitor and suggested that its antitumor action could be linked to its $\mathrm{Na} / \mathrm{K}$-ATPase binding properties. Perillyl alcohol reduced $21-26 \mathrm{kDa}$ proteins isoprenylation to $50 \%$ of the control level at a concentration of $1 \mathrm{mM}$ but had no effect on the isoprenylation of 67,47 , or $17 \mathrm{kDa}$ proteins [138]. Sahin and collaborators [139] demonstrated that perillyl alcohol selectively induced G0/G1 arrest and apoptosis in
Bcr/Abl-transformed myeloid cell lines. In the same year Satomi and collaborators [140] demonstrated induction of AP-1 activity by perillyl alcohol in breast cancer cells. Ahn and collaborators [141] verified that cytotoxicity of perillyl alcohol against cancer cells is potentiated by hyperthermia. Ren and Gould [142] demonstrated an inhibition of ubiquinone and cholesterol synthesis by perillyl alcohol, and the authors suggested that these effects may contribute to the antitumor activity of the molecule. Manassero and collaborators [108] tested the ability of perillyl alcohol to inhibit protein prenylation enzymes in vitro and verified that it is a weak inhibitor of both mammalian and yeast forms of protein farnesyltransferase and protein geranylgeranyl transferase. In NIH3T3 cells, Ren and collaborators [143] verified that perillyl alcohol inhibited the in vivo prenylation of specific proteins by type I and type II geranylgeranyl-protein transferases but not by farnesyl-protein transferase. Elegbede and Gould [121] investigated the effects of perillyl alcohol at the initiation stage of aflatoxin B1-induced hepatocarcinogenesis. In this study, analysis of liver samples showed that perillyl alcohol significantly inhibited aflatoxin-DNA adduct formation in hepatocytes, and therefore this monoterpene may have potential for use as a chemopreventive agent against aflatoxin-induced liver cancer. Balassiano and collaborators [144] observed the effects of perillyl alcohol in the glial C6 cell line in vitro and antimetastatic activity in a chorioallantoic membrane model and suggested a possible use for perillyl alcohol as an in vivo antimetastatic drug. Da Fonseca and collaborators [145] discussed perillyl alcohol intranasal delivery as a potential antitumor agent. The chemopreventive effect of topical application of perillyl alcohol on DMBAinitiated and 12-O-tetradecanoylphorbol-13-acetate- (TPA-) promoted skin tumorigenesis and its mechanisms of action were investigated in Swiss albino mice [146]. The mechanisms of action of perillyl alcohol were investigated in advanced rat mammary carcinomas by Ariazi and collaborators [147], and it was found that it activated the TGF-beta signaling pathway and induced cytostasis and apoptosis in mammary carcinomas. These authors also identified differentially expressed genes in mammary carcinomas treated with perillyl alcohol. Perillyl alcohol-mediated cell cycle arrest was found to precede apoptosis, which raised the possibility that the primary effect of perillyl alcohol is to induce G0/G1 arrest, with apoptosis as a consequence of this growth arrest [139, 148]. Using a novel and innovative approach, Lebedeva and collaborators [149] demonstrated that chemoprevention by perillyl alcohol, coupled with viral gene therapy, reduced pancreatic cancer pathogenesis. Perilla aldehyde is a major intermediary metabolite of perillyl alcohol in the rat in vivo and may contribute to the anticancer effect of perillyl alcohol [150]. Phillips and collaborators [151] investigated the pharmacokinetics of active drug metabolites after oral administration of perillyl alcohol in dogs. Samaila and collaborators [126] verified that perillyl alcohol has potential as a radiosensitizer in chemoradiation therapy of head and neck cancers. Rajesh and collaborators [152] also studied the role of perillyl alcohol as a radiosensitizer and chemosensitizer in malignant glioma. Ripple and collaborators [153] conducted a phase I dose-escalation trial of perillyl alcohol given p.o. 
on a continuous basis 4 times per day to characterize its maximum tolerated dose, toxicities, pharmacokinetic profile, and antitumor activity. This study was conducted after a phase I clinical trial of perillyl alcohol in which no objective tumor responses were noted when it was administered daily [154]. A phase I trial of perillyl alcohol in patients with advanced solid tumors was conducted by Azzoli and collaborators [155]. A phase I pharmacokinetic trial of perillyl alcohol in patients with refractory solid malignancies was performed by Hudes and collaborators [156], in which the authors verified that perillyl alcohol at $1600-2100 \mathrm{mg} / \mathrm{m}^{2}$ p.o. 3 times daily was well tolerated on a 14-day on/14-day off dosing schedule. A phase II trial of perillyl alcohol in patients with metastatic colorectal cancer was conducted by Meadows and collaborators [157], in which the authors found that oral perillyl alcohol did not have clinical antitumor activity when used for patients with advanced colorectal carcinoma, despite preclinical evidence of anticancer activity.

1.20. 1,8-Cineole/Eucalyptol. The cytotoxicity of 1,8-cineole was investigated against SK-OV-3, HO-8910, and Bel-7402 cell lines [158]. Monoterpene 1,8-cineole demonstrated moderate cytotoxicity in Hep G2, HeLa, MOLT-4, K-562, and CTVR-1 cell lines [14]. Asanova and collaborators [159] demonstrated that 1,8-cineole had moderate antioxidant and cytotoxic properties and pronounced analgesic and antitumor activity. Cha and collaborators [160] found that 1,8cineole induced apoptosis in $\mathrm{KB}$ cells via mitochondrial stress and caspase activation. Bhattacharjee and Chatterjee [109] promoted the identification of proapoptotic, antiinflammatory, antiproliferative, anti-invasive, and potential antiangiogenic activities of eucalyptol by employing a dual reverse virtual screening protocol. A probabilistic set of antitumor targets was generated, which can be further confirmed by in vivo and in vitro experiments.

1.21. Perilla Aldehyde. Perilla aldehyde showed marked antioxidant and radical scavenging activity using different model systems, including 1,1-diphenyl-2-picrylhydrazyl radical (DPPH) and beta-carotene-linoleic acid blenching assays, and also inhibited MCF-7, K562, and PC-12 cell growth in a dose- and time-dependent manner, with $\mathrm{IC}_{50}$ values that ranged from $0.25-5.0 \mathrm{mmol} / \mathrm{L}$ [106].

1.22. Terpinen-4-ol. Terpinen-4-ol showed cytotoxicity against Hep G2, HeLa, MOLT-4, K-562, CTVR-1 [14], and human M14 melanoma cells [161]. Bozzuto and collaborators [162] demonstrated that this monoterpene interfered with the migration and invasion processes of drug-sensitive and drug-resistant melanoma cells. Terpinen-4-ol also induced necrosis and cell cycle arrest in murine cancer cell lines [163].

1.23. Citral. Citral is cytotoxic against P388 mouse leukemia [164], HeLa [165], Ishikawa, and ECC-1 cancer cells [166]. Xia and collaborators [167] reported that citral had a therapeutic effect on leukemia.
1.24. Carvone. Carvone inhibited viability and proliferation of Hep-2 cells in a dose-dependent manner, with morphological analysis suggesting an involvement of apoptosis. In the SOS chromotest, carvone did not cause DNA damage at nontoxic doses. In the DNA repair test, a marked dosedependent differential toxicity was observed [35]. Carvone also presented a dose-dependent cytotoxic effect against HeLa cells [168]. In contrast, more recently, Aydin and collaborators [169] reported that carvone could be a promising anticancer agent to improve brain tumor therapy. In the work of Jaafari and collaborators [46], the authors compared the cytotoxic effects and molecular mechanisms of five monoterpenes: carvacrol, thymol, carveol, carvone, and isopulegol. The results showed that the carvacrol is the most active monoterpene. However, the data of $\mathrm{IC}_{50}(0.17 \mu \mathrm{M}$ on K562 cells) showed that carvone has significant cytotoxicity. Although carvacrol induce cell cycle arrest in $\mathrm{S}$ phase, no effect on cell cycle was observed for carvone.

1.25. Alpha- and Beta-Pinene. Alpha- and beta-pinene showed cytotoxicity on tumor lymphocytes [106] and in others different tumor and nontumor cell lines [157, 170]. In the same cases, this cytotoxicity was comparable to doxorubicin [171]. Alpha- and beta-pinene did not show antitumor activity in vivo using the Ehrlich ascites tumor model [157]. The cytotoxic potential of alpha-pinene was investigated in SK-OV-3, HO-8910, Bel-7402 [158], and U937 cell lines [172]. The cytotoxicity of alpha-pinene was comparable to doxorubicin [173]. Bhattacharjee and Chatterjee [109] promoted the identification of proapoptotic, antiinflammatory, antiproliferative, anti-invasive, and potential antiangiogenic activities of alpha-pinene by employing a dual reverse virtual screening protocol. Jin and collaborators [174] demonstrated that alpha-pinene triggered oxidative stress and related signaling pathways in A549 and HepG2 cells. The cytotoxic potential of beta-pinene was investigated in MCF-7, A375, and HepG2 cancer cells [94] and in other different tumor and nontumor cell lines [50].

1.26. Geraniol. Carnesecchi and collaborators [175] demonstrated that this monoterpene sensitized human colonic cancer cells to 5-Fluorouracil treatment in vitro. In a later work, Carnesecchi and collaborators [176] demonstrated that geraniol modulated DNA synthesis and potentiated 5fluorouracil effects on human colon tumor xenografts. Bhattacharjee and Chatterjee [109] promoted the identification of proapoptotic, anti-inflammatory, antiproliferative, antiinvasive, and potential antiangiogenic activities of geraniol by employing a dual reverse virtual screening protocol. A probabilistic set of antitumor targets was generated, which can be further confirmed by in vivo and in vitro experiments. Geraniol suppressed pancreatic tumor growth without significantly affecting blood cholesterol levels [128]. Polo and de Bravo [177] demonstrated multiple effects of geraniol on mevalonate and lipid metabolism in Hep G2 cells that affected cell proliferation. More recently, Crespo and collaborators [178] reported transcriptional and posttranscriptional inhibition of HMGCR and PC biosynthesis by geraniol in 2 Hep-G2 cell 
proliferation-linked pathways. Geraniol inhibited the activity of HMG-CoA reductase, which reduced the possibility of cancer growth [112]. Geraniol also inhibited growth and polyamine biosynthesis in human colon cancer cells [179]. Zheng and collaborators [122] suggested that geraniol showed promise as a chemopreventive agent because it showed strong GST-inducing activity in the mucosa of the small intestine and the large intestine. Ong and collaborators [180] and Cardozo and collaborators [181] suggested that geraniol showed promising chemopreventive effects against hepatocarcinogenesis. More recently, Madankumar and collaborators [182] evidenced that geraniol presents chemopreventive potential against oral carcinogenesis.

1.27. Citronellol. Citronellol exhibited weak cytotoxic effects against HL60 tumor cells [183].

1.28. Camphene. Wright and collaborators [165] verified that the cytotoxic activity of humulene on MCF-7 cells was antagonized by camphene.

1.29. Linalool. Linalool showed cytotoxic effects on $\mathrm{C} 32$ cells [94], BCC-1/KMC, AGS, RTCC-1/KMC, U 2 OS, HeLa, H520, H661, OSCC-1/KMC, J82 [184], human leukemia, and lymphoma cell lines [185], amelanotic melanoma C32 cells, and renal cell adenocarcinoma cells [186]. Usta and collaborators [187] verified that linalool decreased HepG2 viability by inhibiting mitochondrial complexes I and II, increasing reactive oxygen species, and decreasing ATP and GSH levels. Gu and collaborators [188] showed that linalool preferentially induced robust apoptosis of a variety of leukemia cells by upregulation of p53 and cyclin-dependent kinase inhibitors. A study conducted by Ravizza and collaborators [189] demonstrated that linalool reversed doxorubicin resistance in human breast adenocarcinoma cells. Maeda and collaborators [190] demonstrated that linalool significantly suppressed HL60 cell proliferation, induced apoptosis, and promoted cell differentiation. The effect of linalool on doxorubicin-induced antitumor activity was evaluated by Miyashita and Sadzuca [191].

1.30. Cymene. The anticancer activity of $p$-cymene was studied by Bourgou and collaborators [50]. Ferraz and collaborators [9] investigated the cytotoxic effect of p-cymene in three cell lines: HepG2, K562, and B16-F10. The results demonstrated that $p$-cymene was cytotoxic only to B16-F10 cell lines, showing $\mathrm{IC}_{50}=20.06 \mu \mathrm{g} / \mathrm{mL}$.

1.31. Terpinen-4-ol and $\alpha$-Terpinolene. Badary [54] investigated the cytotoxicity of terpinen-4-ol against two different cell lines, A-549 and DLD-1. For both cell lines, this monoterpene induced weak cytotoxicity. In another study, the cytotoxicity of the Helichrysum gymnocephalum essential oil was evaluated [192]. In addition, this work aimed to establish correlations between the identified compounds and their biological activities (antiplasmodial and cytotoxic). They reviewed researches for essential oils having an activity against $P$. falciparum and/or on MCF-7 cell line in order to identify, by correlation, the main active compounds. The $\alpha$ terpinolene, present in the oil, showed a higher relationship with the cytotoxic activity against MCF-7 cell [192].

\section{Conclusions}

Several studies have shown in vitro and in vivo antitumor activity of many essential oils obtained from plants. The antitumor activity of essential oils of many species has been related to the presence of monoterpenes in their composition [8-12]. This review shows that many monoterpenes are being examined for in vitro and in vivo antitumor activity, presenting important results that provide insights for the use of such compounds for the treatment of cancer. In addition, some studies show that monoterpenes are already in clinical phase trials for drug development, as in the case of Perillyl alcohol [145]. However, despite many studies showing the evaluation of possible mechanisms of action of these compounds, the majority of studies still present only preliminary screening data and therefore do not describe any mechanism of action. For these studies, the monoterpenes are classified only as "active." Thus, additional research is needed to be developed to elucidate how various monoterpenes act to inhibit the proliferation and to induce tumor cell death.

\section{Abbreviations \\ DMBA: $\quad$ 7,12-Dimethylbenz $[\alpha]$ anthracene \\ DEN: Diethylnitrosamine \\ ROS: $\quad$ Reactive oxygen species \\ GSH: $\quad$ Reduced glutathione \\ NMU: $\quad$ N-Nitroso-N-methylurea \\ NNK: 4-(Methylnitrosamino)-1-(3-pyridyl)-1- butanone \\ HMG-CoA: 3-Hydroxy-3-methylglutaryl-CoA \\ GST: Glutathione S-transferase \\ NDEA: N-Nitrodiethylamine.}

\section{Conflict of Interests}

The authors declare that there is no conflict of interests regarding the publication of this paper.

\section{Acknowledgments}

This research was supported by Conselho Nacional de Desenvolvimento Científico e Tecnológico (CNPq) and Coordenação de Aperfeiçoamento de Pessoal de Nível Superior (CAPES).

\section{References}

[1] D. Hanahan and R. A. Weinberg, "Hallmarks of cancer: the next generation,” Cell, vol. 144, no. 5, pp. 646-674, 2011.

[2] Brasil Ministério da Saúde and Instituto Nacional de Câncer, Políticas e Ações para Prevenção do Câncer no Brasil Alimentação, Nutrição e Atividade Física, INCA, Rio de Janeiro, Brazil, 2009. 
[3] J. C. L. R. Pita, A. L. Xavier, T. K. G. de Sousa et al., "In vitro and in vivo antitumor effect of trachylobane-360, a diterpene from Xylopia langsdorffiana," Molecules, vol. 17, no. 8, pp. 9573-9589, 2012.

[4] T. Efferth, "Cancer therapy with natural products and medicinal plants," Planta Medica, vol. 76, pp. 1035-1036, 2010.

[5] D. P. De Sousa, Medicinal Essential Oils: Chemical, Pharmacological and Therapeutic Aspects, Nova Science Publishers, New York, NY, USA, 1st edition, 2012.

[6] P. Rasoanaivo, R. F. Randriana, F. Maggi et al., "Chemical composition and biological activities of the essential oil of Athanasia brownie Hochr. (Asteraceae) endemic to Madagascar," Chemistry \& Biodiversity, vol. 10, no. 10, pp. 1876-1886, 2013.

[7] B. Zapata, L. G. Betancur, C. Duran, and E. Stashenko, "Cytotoxic activity of Asteraceae and Verbenaceae family essential oils," Journal of Essential Oil Research, vol. 6, pp. 50-57, 2014.

[8] S. P. Piaru, R. Mahmud, A. M. S. A. Majid, S. Ismail, and C. N. Man, "Chemical composition, antioxidant and cytotoxicity activities of the essential oils of Myristica fragrans and Morinda citrifolia," Journal of the Science of Food and Agriculture, vol. 92, pp. 593-597, 2012.

[9] R. P. C. Ferraz, D. S. Bomfim, N. C. Carvalho et al., "Cytotoxic effect of leaf essential oil of Lippia gracilis Schauer (Verbenaceae)," Phytomedicine, vol. 20, pp. 615-621, 2013.

[10] F. F. Maggi, R. F. Randriana, P. Rasoanaivo et al., "Chemical composition and in vitro biological activities of the essential oil of Vepris macrophylla (BAKER) I.VERD. endemic to Madagascar," Chemistry \& Biodiversity, vol. 10, no. 3, pp. 356-365, 2013.

[11] M. Nikolić, J. Glamočlija, I. C. F. R. Ferreira et al., "Chemical composition, antimicrobial, antioxidant and antitumor activity of Thymus serpyllum L., Thymus algeriensis Boiss. and Reut and Thymus vulgaris L. essential oils," Industrial Crops and Products, vol. 52, pp. 183-190, 2014.

[12] D. D. Deb, G. Parimala, D. S. Saravana, and T. Chakraborty, "Effect of thymol on peripheral blood mononuclear cell PBMC and acute promyelotic cancer cell line HL-60," ChemicoBiological Interactions, vol. 193, no. 1, pp. 97-106, 2011.

[13] W. S. Itani, S. H. El-Banna, S. B. Hassan, R. L. Larsson, A. Gali-Muhtasib, and H. U, "Anti-colon cancer components from Lebanese sage (Salvia libanotica) essential oil: mechanistic basis," Cancer Biology \& Therapy, vol. 7, pp. 1765-1773, 2008.

[14] A. J. Hayes, D. N. Leach, J. L. Markham, and B. Markovic, "In vitro cytotoxicity of Australian tea tree oil using human cell lines," Journal of Essential Oil Research, vol. 9, pp. 575-582, 1997.

[15] I. Lampronti, A. M. Saab, and R. Gambari, "Antiproliferative activity of essential oils derived from plants belonging to the Magnoliophyta division," International Journal of Oncology, vol. 29, pp. 989-995, 2006.

[16] S. B. Hassan, H. Gali-Muhtasib, H. Goeransson, and R. Larsson, "Alpha terpineol: a potential anticancer agent which acts through suppressing NF- $\kappa \mathrm{B}$ signalling," Anticancer Research, vol. 30, pp. 1911-1919, 2010.

[17] K. Okamura, S. Iwakami, and T. Matsunaga, "Biological activity of monoterpenes from trees," Toyama-Ken Yakuji Kenkyusho Nenpo, vol. 20, pp. 95-101, 1993.

[18] H. F. Lu, J. Y. Liu, S. C. Hsueh et al., “(-)-Menthol inhibits WEHI-3 leukemia cells in vitro and in vivo," In Vivo, vol. 21, no. 2, pp. 285-289, 2007.

[19] J. P. Lin, H. F. Lu, J. H. Lee et al., "Menthol inhibits DNA topoisomerases I, II alpha and beta and promotes NF-kappaB expression in human gastric cancer SNU-5 cells," Anticancer Res, vol. 25, pp. 2069-2074, 2005.

[20] E. J. Park, S. H. Kim, B. J. Kim, S. Y. Kim, I. So, and J. H. Jeon, "Menthol enhances an antiproliferative activity of $1 \alpha$,25-dihydroxyvitamin D3 in LNCaP cells," Journal of Clinical Biochemistry and Nutrition, vol. 44, no. 2, pp. 125-130, 2009.

[21] Y. Wang, X. Wang, Z. Yang, G. Zhu, D. Chen, and Z. Meng, "Menthol inhibits the proliferation and motility of prostate cancer DU145 cells," Pathology Oncology Research, vol. 18, no. 4, pp. 903-910, 2005.

[22] Q. Li, X. Wang, Z. Yang, B. Wang, and S. Li, "Menthol induces cell death via the TRPM8 channel in the human bladder cancer cell line T24," Oncology, vol. 77, no. 6, pp. 335-341, 2009.

[23] Y. Okamoto, T. Ohkubo, T. Ikebe, and J. Yamazaki, "Blockade of TRPM8 activity reduces the invasion potential of oral squamous carcinoma cell lines," International Journal of Oncology, vol. 40, pp. 1431-1440, 2012.

[24] E. Matsumura, Y. Morita, T. Date et al., "Cytotoxicity of the hinokitiol-related compounds, $\gamma$-thujaplicin and $\beta$-dolabrin," Biological \& Pharmaceutical Bulletin, vol. 24, pp. 299-302, 2001.

[25] Y. Morita, E. Matsumura, H. Tsujibo et al., "Biological activity of a-thujaplicin, the minor component of Thujopsis dolabrata Sieb. et Zucc. var. hondai Makino," Biological \& Pharmaceutical Bulletin, vol. 24, pp. 607-611, 2001.

[26] D. Slamenova, E. Horvathova, L. Wsolova, M. Sramkova, and J. Navarova, "Investigation of anti-oxidative, cytotoxic, DNAdamaging and DNA-protective effects of plant volatiles eugenol and borneol in human-derived HepG2, Caco-2 and VH10 cell lines," Mutation Research, vol. 677, no. 1-2, pp. 46-52, 2009.

[27] J. Su, H. Lai, J. Chen et al., "Natural borneol, a monoterpenoid compound, potentiates selenocystine-induced apoptosis in human hepatocellular carcinoma cells by enhancement of cellular uptake and activationof ROS-mediated DNA damage," PLoS ONE, vol. 8, Article ID e63502, 2013.

[28] T. Efferth, A. Olbrich, A. Sauerbrey, D. D. Ross, E. Gebhart, and M. Neugebauer, "Activity of ascaridol from the anthelmintic herb Chenopodium anthelminticum L. against sensitive and multidrug-resistant tumor cells," Anticancer Research, vol. 22, pp. 4221-4224, 2002.

[29] D. P. Bezerra, J. D. B. Marinho Filho, A. P. N. N. Alves et al., "Antitumor activity of the essential oil from the leaves of Croton regelianus and its component ascaridole," Chemistry \& Biodiversity, vol. 6, pp. 1224-1231, 2009.

[30] S. R. Gedara, "Terpenoid content of the leaves of Thymus algeriensis Boiss," Mansoura Journal of Pharmaceutical Sciences, vol. 24, pp. 133-143, 2008.

[31] A. Jaafari, H. Ait Mouse, E. M. Rakib et al., "Chemical composition and antitumor activity of different wild varieties of Moroccan thyme," Revista Brasileira de Farmacognosia, vol. 17, pp. 477-491, 2007.

[32] E. Horvathova, M. Sramkova, J. Labaj, and D. Slamenovam, "Study of cytotoxic, genotoxic and DNA-protective effects of selected plant essential oils on human cells cultured in vitro," Neuroendocrinology Letters, vol. 27, pp. 44-47, 2006.

[33] E. Horvathova, V. Turcaniova, and D. Slamenova, "Comparative study of DNA-damaging and DNA-protective effects of selected components of essential plant oils in human leukemic cells K562," Neoplasma, vol. 54, pp. 478-483, 2007.

[34] D. Slamenova, E. Horvathova, M. Sramkova, and L. Marsalkova, "DNA-protective effects of two components of essential plant oils carvacrol and thymol on mammalian cells cultured in vitro," Neoplasma, vol. 54, pp. 108-112, 2007. 
[35] A. Stammati, P. Bonsi, F. Zucco, R. Moezelaar, H.-L. Alakomi, and A. von Wright, "Toxicity of selected plant volatiles in microbial and mammalian short-term assays," Food and Chemical Toxicology, vol. 37, no. 8, pp. 813-823, 1999.

[36] Q. H. Yin, F. X. Yan, X. Y. Zu et al., "Anti-proliferative and pro-apoptotic effect of carvacrol on human hepatocellular carcinoma cell line HepG-2," Cytotechnology, vol. 64, pp. 43-51, 2012.

[37] K. M. Arunasree, "Anti-proliferative effects of carvacrol on a human metastatic breast cancer cell line, MDA-MB 231," Phytomedicine, vol. 17, no. 8-9, pp. 581-588, 2010.

[38] S. Jayakumar, A. Madankumar, S. Asokkumar et al., "Potential preventive effect of carvacrol against diethylnitrosamineinduced hepatocellular carcinoma in rats," Molecular and Cellular Biochemistry, vol. 360, pp. 51-60, 2012.

[39] A. Jaafari, H. A. Mouse, L. A. M'Bark et al., "Differential antitumor effect of essential oils and their major components of Thymus broussonettii: relationship to cell cycle and apoptosis induction," Herba Polonica Journal, vol. 55, pp. 36-50, 2009.

[40] H. Zeytinoglu, Z. Incesu, and K. H. C. Baser, "Inhibition of DNA synthesis by carvacrol in mouse myoblast cells bearing a human N-RAS oncogene," Phytomedicine, vol. 10, pp. 292-299, 2003.

[41] E. Ipek, H. Zeytinoglu, S. Okay, B. A. Tuylu, M. Kurkcuoglu, and K. H. C. Baser, "Genotoxicity and antigenotoxicity of Origanum oil and carvacrol evaluated by Ames Salmonella/microsomal test," Food Chemistry, vol. 93, no. 3, pp. 551-556, 2005.

[42] A. Ozkan and A. Erdogan, "A comparative evaluation of antioxidant and anticancer activity of essential oil from Origanum onites (Lamiaceae) and its two major phenolic components," Turkish Journal of Biology, vol. 35, pp. 735-742, 2011.

[43] M. Zeytinoglu, S. Aydin, Y. Ozturk, K. Husnu, and C. Baser, "Inhibitory effects of carvacrol on DMBA induced pulmonary tumorigenesis in rats," Acta Pharmaceutica Turcica, vol. 40, no. 2, pp. 93-98, 1998.

[44] C. Hirobe, Z. S. Qiao, K. Takeya, and H. Itokawa, "Cytotoxic principles from Majorana syriaca," Nature Medicine, vol. 52, pp. 74-77, 1998.

[45] A. Paramasivam, S. Sambantham, J. Shabnam et al., "Anticancer effects of thymoquinone in mouse neuroblastoma (Neuro-2a) cells through caspase-3 activation with downregulation of XIAP," Toxicology Letters, vol. 213, pp. 151-159, 2012.

[46] A. Jaafari, M. Tilaoui, H. A. Ait Mouse et al., "Comparative study of the antitumor effect of natural monoterpenes: relationship to cell cycle analysis," Revista Brasileira de Farmacognosia, vol. 22, pp. 534-540, 2012.

[47] S. Ivankovic, R. Stojkovic, M. Jukic, M. Milos, and M. Jurin, "The antitumor activity of thymoquinone and thymohydroquinone in vitro and in vivo," Experimental Oncology, vol. 28, pp. 220-224, 2006.

[48] H. A. Johnson, L. L. Rogers, M. L. Alkire, T. G. McCloud, and J. L. McLaughlin, "Bioactive monoterpenes from Monarda fistulosa (Lamiaceae)," Natural Product Letters, vol. 11, no. 4, pp. 241-250, 1998.

[49] S. Rooney and M. F. Ryan, "Effects of alpha-hederin and thymoquinone, constituents of Nigella sativa, on human cancer cell lines," Anticancer Research, vol. 25, pp. 2199-2204, 2005.

[50] S. Bourgou, A. Pichette, B. Marzouk, and J. Legault, "Bioactivities of black cumin essential oil and its main terpenes from Tunisia," South African Journal of Botany, vol. 76, pp. 210-216, 2010.
[51] V. Cecarini, L. Quassinti, A. di Blasio et al., "Effects of thymoquinone on isolated and cellular proteasomes," FEBS Journal, vol. 277, pp. 2128-2141, 2010.

[52] S. H. Jafri, J. Glass, R. Shi, S. Zhang, M. Prince, and H. Kleiner-Hancock, "Thymoquinone and cisplatin as a therapeutic combination in lung cancer: in vitro and in vivo," Journal of Experimental \& Clinical Cancer Research, vol. 29, p. 87, 2010.

[53] O. A. Badary, M. N. Nagi, O. A. al-Shabanah, H. A. al-Sawaf, M. O. al-Sohaibani, and A. M. al-Bekairi, "Thymoquinone ameliorates the nephrotoxicity induced by cisplatin in rodents and potentiates its antitumor activity," Canadian Journal of Physiology and Pharmacology, vol. 75, pp. 1356-1361, 1997.

[54] O. A. Badary, "Thymoquinone attenuates ifosfamide-induced Fanconi syndrome in rats and enhances its antitumor activity in mice," Journal of Ethnopharmacology, vol. 67, no. 2, pp. 135$142,1999$.

[55] S. Banerjee, A. O. Kaseb, Z. Wang et al., "Antitumor activity of gemcitabine and oxaliplatin is augmented by thymoquinone in pancreatic cancer," Cancer Research, vol. 69, pp. 5575-5583, 2009.

[56] G. Sethi, K. S. Ahn, and B. B. Aggarwal, " Targeting nuclear factor- $\kappa \mathrm{B}$ activation pathway by thymoquinone: role in suppression of antiapoptotic gene products and enhancement of apoptosis," Molecular Cancer Research, vol. 6, no. 6, pp. 10591070, 2008.

[57] H. Gali-Muhtasib, D. Kuester, C. Mawrin et al., "Thymoquinone triggers inactivation of the stress response pathway sensor CHEK1 and contributes to apoptosis in colorectal cancer cells," Cancer Research, vol. 68, pp. 5609-5618, 2008.

[58] F. Li, P. Rajendran, and G. Sethi, “Thymoquinone inhibits proliferation, induces apoptosis and chemosensitizes human multiple myeloma cells through suppression of signal transducer and activator of transcription 3 activation pathway," British Journal of Pharmacology, vol. 161, no. 3, pp. 541-554, 2010.

[59] O. A. Badary and A. M. G. El-Din, "Antitumor activity of thymoquinone against fibrosarcoma tumorigenesis," Cancer Molecular Biology, vol. 7, no. 3, pp. 1515-1526, 2000.

[60] O. A. Badary and E. A. M. Gamal, "Inhibitory effects of thymoquinone against 20-methylcholanthrene-induced fibrosarcoma tumorigenesis," Cancer Detection and Prevention, vol. 25, pp. 362-368, 2001.

[61] J. Barron, H. Benghuzzi, and M. Tucci, "Effects of thymoquinone and selenium on the proliferation of MG 63 cells in tissue culture," Biomedical Sciences Instrumentation, vol. 44, pp. 434-440, 2008.

[62] M. Roepke, A. Diestel, K. Bajbouj et al., "Lack of p53 augments thymoquinone-induced apoptosis and caspase activation in human osteosarcoma cells," Cancer Biology \& Therapy, vol. 6, pp. 160-169, 2007.

[63] L. Peng, A. Liu, Y. Shen et al., "Antitumorandanti-angiogenesis effects ofthymoquinoneon osteosarcoma through the NF- $\kappa \mathrm{B}$ pathway," Oncology Reports, vol. 29, pp. 571-578, 2013.

[64] L. S. Yazan, W. K. Ng, G. Al-Naqeeb, and M. Ismail, "Cytotoxicity of thymoquinone (TQ) from Nigella sativa towards human cervical carcinoma cells (HeLa)," Journal of Pharmacy Research, vol. 2, pp. 585-589, 2009.

[65] N. El-Najjar, M. Chatila, H. Moukadem et al., "Reactive oxygen species mediate thymoquinone-induced apoptosis and activate ERK and JNK signaling," Apoptosis, vol. 15, pp. 183-195, 2010.

[66] F. Wilson-Simpson, S. Vance, and H. Benghuzzi, "Physiological responses of ES-2 ovarian cell line following administration of 
epigallocatechin-3-gallate (EGCG), thymoquinone (TQ), and selenium (SE)," Biomedical Sciences Instrumentation, vol. 43, pp. 378-383, 2007.

[67] N. Farah, H. Benghuzzi, M. Tucci, and Z. Cason, "The effects of isolated antioxidants from black seed on the cellular metabolism of A549 cells," Biomedical Sciences Instrumentation, vol. 41, pp. 211-216, 2005.

[68] H. Zubair, H. Y. Khan, A. Sohail et al., "Redox cycling of endogenous copper bythymoquinoneleads to ROS-mediated DNA breakage and consequent cell death: putativeanticancermechanism of antioxidants," Cell Death \& Disease, vol. 4, p. e660, 2013.

[69] W. H. Talib and M. M. Abu Khader, "Combinatorial effects ofthymoquinoneon theanticanceractivityand hepatotoxicity of the prodrug CB 1954," Scientia Pharmaceutica, vol. 81, pp. 519530, 2013.

[70] L. R. Richards, P. Jones, J. Hughes, H. Benghuzzi, and M. Tucci, "LNCaP cells exposed to ceramic drug delivery treatment with epigallocatechin-3-gallate, thymoquinone, and tannic acid," Biomedical Sciences Instrumentation, vol. 43, pp. 242-247, 2007.

[71] L. R. Richards, P. Jones, H. Benghuzzi, and M. Tucci, "A comparison of the morphological changes associated with conventional and sustained treatment with epigallocatechin3-gallate, thymoquinone, and tannic acid on LNCaP cells," Biomedical Sciences Instrumentation, vol. 44, pp. 465-470, 2008.

[72] M. A. El-Mahdy, Q. Zhu, Q. Wang, G. Wani, and A. A. Wani, "Thymoquinone induces apoptosis through activation of caspase- 8 and mitochondrial events in p53-null myeloblastic leukemia HL-60 cells," International Journal of Cancer, vol. 117, pp. 409-417, 2005.

[73] P. S. Koka, D. Mondal, M. Schultz, A. B. Abdel-Mageed, and K. C. Agrawal, "Studies on molecular mechanisms of growth inhibitory effects of thymoquinone against prostate cancer cells: role of reactive oxygen species," Experimental Biology and Medicine, vol. 235, pp. 751-760, 2010.

[74] A. M. Shoieb, M. Elgayyar, P. S. Dudrick, J. L. Bell, and P. K. Tithof, "In vitro inhibition of growth and induction of apoptosis in cancer cell lines by thymoquinone," International Journal of Oncology, vol. 22, pp. 107-113, 2003.

[75] S. A. Hassan, W. A. Ahmed, F. M. Galeb, M. A. El-Taweel, and F. A. Abu-Bedair, "In vitro challenge using thymoquinone on hepatocellular carcinoma (HepG2) cell line," Iranian Journal of Pharmaceutical Research, vol. 7, pp. 283-290, 2008.

[76] H. U. Gali-Muhtasib, W. G. A. Kheir, L. A. Kheir, N. Darwiche, and P. A. Crooks, "Molecular pathway for thymoquinoneinduced cell-cycle arrest and apoptosis in neoplastic keratinocytes," Anticancer Drugs, vol. 15, pp. 389-399, 2004.

[77] R. L. Gurung, S. N. Lim, A. K. Khaw et al., "Thymoquinone induces telomere shortening, DNA damage and apoptosis in human glioblastoma cells," PLoS ONE, vol. 5, Article ID e12124, 2010.

[78] H. Satooka and I. Kubo, "Effects of thymol on B16-F10 melanoma cells," Journal of Agricultural and Food Chemistry, vol. 60, pp. 2746-2752, 2012.

[79] A. Abusnina, M. Alhosin, T. Keravis et al., "Down-regulation of cyclic nucleotide phosphodiesterase PDE1A is the key event of p73 and UHRF1 deregulation in thymoquinone-induced acute lymphoblastic leukemia cell apoptosis," Cellular Signalling, vol. 23, pp. 152-160, 2011.

[80] M. P. Torres, M. P. Ponnusamy, S. Chakraborty et al., "Effects of thymoquinone in the expression of mucin 4 in pancreatic cancer cells: implications for the development of novel cancer therapies," Molecular Cancer Therapeutics, vol. 9, pp. 1419-1431, 2010.

[81] D. R. Worthen, O. A. Ghosheh, and P. A. Crooks, "The in vitro anti-tumor activity of some crude and purified components of blackseed, Nigella sativa L.," Anticancer Research, vol. 18, pp. 1527-1532, 1998.

[82] A. el-SA, Q. Zhu, Z. I. Shah et al., "Thymoquinone up-regulates PTEN expression and induces apoptosis in doxorubicinresistant human breast cancer cells," Mutation Research, vol. 706, no. 1-2, pp. 28-35, 2011.

[83] J. Ravindran, H. B. Nair, B. Sung, S. Prasad, R. R. Tekmal, and B. B. Aggarwal, "Thymoquinone poly (lactide-coglycolide) nanoparticles exhibit enhanced anti-proliferative, anti-inflammatory, and chemosensitization potential," Biochemical Pharmacology, vol. 79, no. 11, pp. 1640-1647, 2010.

[84] G. M. Ganea, S. O. Fakayode, J. N. Losso, C. F. Van Nostrum, C. M. Sabliov, and I. M. Warner, "Delivery of phytochemical thymoquinone using molecular micelle modified poly $(\mathrm{D}, \mathrm{L}$ lactide-co-glycolide) (PLGA) nanoparticles," Nanotechnology, vol. 21, no. 28, Article ID 285104, 2010.

[85] A. Wirries, S. Breyer, K. Quint, R. Schobert, and M. Ocker, "Thymoquinone hydrazone derivatives cause cell cycle arrest in p53-competent colorectal cancer cells," Experimental and Therapeutic Medicine, vol. 1, pp. 369-375, 2010.

[86] S. Banerjee, A. S. Azmi, S. Padhye et al., "Structure-activity studies on therapeutic potential of thymoquinone analogs in pancreatic cancer," Pharmaceutical Research, vol. 27, pp. 1146$1158,2010$.

[87] K. Effenberger, S. Breyer, and R. Schobert, “Terpene conjugates of the Nigella sativa seed-oil constituent thymoquinone with enhanced efficacy in cancer cells," Chemistry \& Biodiversity, vol. 7, pp. 129-139, 2010.

[88] N. El-Najjar, R. Ketola, T. A et al., "Impact of protein binding on the analytical detectability and anticancer activity of thymoquinone," The Journal of Biological Chemistry, vol. 4, pp. 97-107, 2011.

[89] O. A. Al-Shabanah, O. A. Badary, M. N. Nagi, N. M. AlGharably, A. C. Al-Rikabi, and A. M. Al-Bekairi, "Thymoquinone protects against doxorubicin-induced cardiotoxicity without compromising its antitumor activity," Journal of Experimental \& Clinical Cancer Research, vol. 17, no. 2, pp. 193-198, 1998.

[90] M. N. Nagi and H. A. Almakki, "Thymoquinone supplementation induces quinone reductase and glutathione transferase in mice liver: possible role in protection against chemical carcinogenesis and toxicity," Phytotherapy Research, vol. 23, pp. 1295-1298, 2009.

[91] Y. Li, C. Yeung, L. C. M. Chiu, Y. Cen, and V. E. C. Ooi, "Chemical composition and antiproliferative activity of essential oil from the leaves of a medicinal herb, Schefflera heptaphylla," Phytotherapy Research, vol. 23, no. 1, pp. 140-142, 2009.

[92] S. Rajput, B. N. Kumar, K. K. Dey, I. Pal, A. Parekh, and M. Mandal, "Molecular targeting of Akt by thymoquinone promotes $G_{1}$ arrest through translation inhibition of cyclin D1 and induces apoptosis in breast cancer cells," Life Sciences, vol. 93, pp. 783-790, 2013.

[93] K. Effenberger-Neidnicht and R. Schobert, "Combinatorial effects of thymoquinone on the anti-cancer activity of doxorubicin," Cancer Chemotherapy and Pharmacology, vol. 67, pp. 867-874, 2011. 
[94] R. Tundis, M. R. Loizzo, M. Bonesi et al., "In vitro cytotoxic effects of Senecio stabianus Lacaita (Asteraceae) on human cancer cell lines," Natural Products Research, vol. 23, no. 18, pp. 1707-1718, 2009.

[95] M. L. Salem, F. Q. Alenzi, and W. Y. Attia, "Thymoquinone, the active ingredient of Nigella sativa seeds, enhances survival and activity of antigen-specific CD8-positive T cells in vitro," British Journal of Biomedical Science, vol. 68, no. 3, pp. 131-137, 2011.

[96] S. Attoub, O. Sperandio, H. Raza et al., "Thymoquinoneas an anticancer agent: evidence from inhibition of cancer cells viability and invasion in vitro and tumor growth in vivo," Fundamental \& Clinical Pharmacology, vol. 27, pp. 557-569, 2013.

[97] M. Lang, M. Borgmann, G. Oberhuber et al., "Thymoquinone attenuates tumor growth in ApcMin mice by interference with Wnt-signaling," Molecular Cancer, vol. 12, p. 41, 2013.

[98] E. Abdelfadil, Y. Cheng, D. Bau et al., "Thymoquinone induces apoptosis in oral câncer cells through P38 $\beta$ Inhibition," The American Journal of Chinese Medicine, vol. 41, pp. 683-696, 2013.

[99] F. Odeh, S. I. Ismail, R. Abu-Dahab, I. S. Mahmoud, and A. Al Bawab, "Thymoquinonein liposomes: a study of loading efficiency and biological activity towards breast cancer," Drug Delivery, vol. 19, pp. 371-377, 2012.

[100] S. Das, K. K. Dey, G. Dey et al., "Antineoplasticand apoptotic potential of traditional medicines thymoquinone and diosgenin in squamous cell carcinoma," PLoS ONE, vol. 7, Article ID e46641, 2012.

[101] M. Alhosin, A. Ibrahim, A. Boukhari et al., "Anti-neoplastic agent thymoquinone induces degradation of $\alpha$ and $\beta$ tubulin proteins in human cancer cells without affecting their level in normal human fibroblasts," Investigational New Drugs, vol. 30, pp. 1813-1819, 2012.

[102] M. M. Saleh, F. A. Hashem, and K. W. Glombitza, "Cytotoxicity and in vitro effects on human cancer cell lines of volatiles of Apium graveolens var. filicinum," Pharmaceutical \& Pharmacological Letters, vol. 8, pp. 97-99, 1998.

[103] S. L. Silva, P. M. Figueiredo, and T. Yano, "Cytotoxic evaluation of essential oil from Zanthoxylum rhoifolium Lam. Leaves," Acta Amazonica, vol. 37, pp. 281-286, 2007.

[104] J. A. Elegbede, T. H. Maltzman, C. E. Elson, and M. N. Gould, "Effects of anticarcinogenic monoterpenes on phase II hepatic metabolizing enzymes," Carcinogenesis, vol. 14, no. 6, pp. 12211223, 1993.

[105] P. L. Crowell, A. S. Ayoubi, and Y. D. Burke, "Antitumorigenic effects of limonene and perillyl alcohol against pancreatic and breast cancer," in Dietary Phytochemicals in Cancer Prevention and Treatment, vol. 401 of Advances in Experimental Medicine and Biology, pp. 131-136, Springer, New York, NY, USA, 1996.

[106] A. Sonboli, M. A. Esmaeili, A. Gholipour, and M. Kanani, "Composition, cytotoxicity and antioxidant activity of the essential oil of Dracocephalum surmandinum from Iran," Natural Product Communications, vol. 5, pp. 341-344, 2010.

[107] M. H. Gelb, F. Tamanoi, K. Yokoyama, F. Ghomashchi, K. Esson, and M. N. Gould, "The inhibition of protein prenyltransferases by oxygenated metabolites of limonene and perillyl alcohol," Cancer Letters, vol. 91, no. 2, pp. 169-175, 1995.

[108] C. A. Manassero, J. R. Girotti, S. Mijailovsky, M. García de Bravo, and M. Polo, "In vitro comparative analysis of antiproliferative activity of essential oil from mandarin peel and its principal component limonene," Natural Product Research, vol. 2, pp. 1475-1478, 2013.
[109] B. Bhattacharjee and J. Chatterjee, "Identification of proapoptopic, anti-inflammatory, anti-proliferative, anti-invasive and anti-angiogenic targets of essential oils in cardamom by dual reverse virtual screening and binding pose analysis," Asian Pacific Journal of Cancer Prevention, vol. 14, pp. 3735-3742, 2013.

[110] J. Ji, L. Zhang, Y. Wu, X. Zhu, S. Lv, and X. Sun, "Induction of apoptosis by d-limonene is mediated by a caspasedependent mitochondrial death pathway in human leukemia cells," Leukemia \& Lymphoma, vol. 47, pp. 2617-2624, 2006.

[111] T. Kawamori, T. Tanaka, Y. Hirose, M. Ohnishi, and H. Mori, "Inhibitory effects of d-limonene on the development of colonic aberrant crypt foci induced by azoxymethane in F344 rats," Carcinogenesis, vol. 17, no. 2, pp. 369-372, 1996.

[112] M. Pattanayak, P. K. Seth, S. Smita, and S. K. Gupta, "Geraniol and limonene interaction with 3-hydroxy-3-methylglutarylCoA (HMG-CoA) reductase for their role as cancer chemopreventive agents," Journal of Proteomics \& Bioinformatics, vol. 2, pp. 466-474, 2009.

[113] X. Chen, O. Shuzo, Y. Li, and R. Han, "Effect of d-limonene, Salvia miltiorrhiza and turmeric derivatives on membrane association and gap junction intercellular communication of ras gene product," Yao Xue Xue Bao, vol. 33, pp. 821-827, 1998.

[114] J. D. Haag, M. J. Lindstrom, and M. N. Gould, "Limoneneinduced regression of mammary carcinomas," Cancer Research, vol. 52, no. 14, pp. 4021-4026, 1992.

[115] S. K. Chander, A. G. B. Lansdown, Y. A. Luqmani et al., "Effectiveness of combined limonene and 4-hydroxy androstenedione in the treatment of NMU-induced rat mammary tumors," The British Journal of Cancer, vol. 69, pp. 879-882, 1994.

[116] C. E. Elson, T. H. Maltzman, J. L. Boston, M. A. Tanner, and M. N. Gould, "Anti-carcinogenic activity of d-limonene during the initiation and promotion/progression stages of DMBA-induced rat mammary carcinogenesis," Carcinogenesis, vol. 9, pp. 331332,1988

[117] K. N. M. Chidambara, G. K. Jayaprakasha, M. Shivappa, and B. S. P. Mantur, "Citrus monoterpenes: potential source of phytochemicals for cancer prevention," in Emerging Trends in Dietary Components for Preventing and Combating Disease, pp. 545-558, 2010.

[118] M. G. Manuele, G. Ferraro, and C. Anesini, "Effect of Tilia $\mathrm{x}$ viridis flower extract on the proliferation of a lymphoma cell line and on normal murine lymphocytes: contribution of monoterpenes, especially limonene," Phytotherapy Research, vol. 22, pp. 1520-1526, 2008.

[119] T. J. Raphael and G. Kuttan, "Preliminary study of antimetastatic activity of naturally occurring monoterpene limonene," Amala Research Bulletin, vol. 23, pp. 99-106, 2003.

[120] M. A. Morse and A. L. Toburen, "Inhibition of metabolic activation of 4-(methylnitrosamino)-1-(3-pyridyl)-1-butanone by limonene," Cancer Letters, vol. 104, pp. 211-217, 1996.

[121] J. A. Elegbede and M. N. Gould, "Monoterpenes reduced adducts formation in rats exposed to aflatoxin B1," African Journal of Biotechnology, vol. 1, pp. 46-49, 2002.

[122] G. Q. Zheng, P. M. Kenney, and L. K. T. Lam, "Potential anticarcinogenic natural products isolated from lemongrass oil and galanga root oil," Journal of Agricultural and Food Chemistry, vol. 41, pp. 153-156, 1993.

[123] T. Parija and B. Ranjan, "Involvement of YY1 and its correlation with c-myc in NDEA induced hepatocarcinogenesis, its prevention by d-limonene," Molecular Biology Reports, vol. 30, no. 1, pp. 41-46, 2003. 
[124] G. Q. Zheng, J. Zhang, P. M. Kenney, and L. K. T. Lam, "Stimulation of glutathione S-transferase and inhibition of carcinogenesis in mice by celery seed oil constituents," ACS Symposium Series, vol. 546, pp. 230-238, 1994.

[125] L. Yeruva, K. J. Pierre, A. Elegbede, R. C. Wang, and S. W. Carper, "Perillyl alcohol and perillic acid induced cell cycle arrest and apoptosis in non-small cell lung cancer cells," Cancer Letters, vol. 257, pp. 216-226, 2007.

[126] D. Samaila, B. J. Toy, C. Wang Robert, and A. Elegbede, "Monoterpenes enhanced the sensitivity of head and neck cancer cells to radiation treatment in vitro," Anticancer Research, vol. 24, no. 5, pp. 3089-3095, 2004.

[127] J. M. Stark, Y. D. Burke, J. H. McKinzie, S. A. Ayoubi, and P. L. Crowell, "Chemotherapy of pancreatic cancer with the monoterpene perillyl alcohol," Cancer Letters, vol. 96, no. 1, pp. 15-21, 1995.

[128] Y. D. Burke, M. J. Stark, S. L. Roach, S. E. Sen, and P. L. Crowell, "Inhibition of pancreatic cancer growth by the dietary isoprenoids farnesol and geraniol," Lipids, vol. 32, no. 2, pp. 151156, 1997.

[129] K. R. Stayrook, J. H. Mckinzie, L. H. Barbhaiya, and P. L. Crowell, "Effects of the antitumor agent perillyl alcohol on $\mathrm{H}$-Ras vs. K-Ras farnesylation and signal transduction in pancreatic cells," Anticancer Research, vol. 18, pp. 823-828, 1998.

[130] K. R. Stayrook, J. H. Mckinzie, Y. D. Burke, Y. A. Burke, and P. L. Crowell, "Induction of the apoptosis-promoting protein Bak by perillyl alcohol in pancreatic ductal adenocarcinoma relative to untransformed ductal epithelial cells," Carcinogenesis, vol. 18, pp. 1655-1658, 1997.

[131] I. V. Lebedeva, Z. Su, N. Vozhilla et al., "Chemoprevention by perillyl alcohol coupled with viral gene therapy reduces pancreatic cancer pathogenesis," Molecular Cancer Therapeutics, vol. 7, pp. 2042-2050, 2008.

[132] T. Sundin, D. M. Peffley, D. Gauthier, and P. Hentosh, "The isoprenoid perillyl alcohol inhibits telomerase activity in prostate câncer cells," Biochimie, vol. 94, pp. 2639-2648, 2012.

[133] Y. Chen and D. Hu, "Effects of POH in combination with STI571 on the proliferation and apoptosis of K562 cells," Journal of Huazhong University of Science and Technology [Medical Sciences], vol. 24, pp. 41-44, 2004.

[134] S. S. Clark, "Perillyl alcohol Iinduces c-Myc-dependent apoptosis in Bcr/Abl-transformed leukemia cells," Oncology, vol. 70, pp. 13-18, 2006.

[135] H. Loutrari, M. Hatziapostolou, V. Skouridou et al., "Perillyl alcohol is an angiogenesis inhibitor," Journal of Pharmacology and Experimental Therapeutics, vol. 311, pp. 568-575, 2004.

[136] H. Loutrari, V. Skouridou, F. N. Kolisis, C. Roussos, and A. Papapetropoulos, "Perillyl alcohol attenuates in vitro angiogenesis, modulates angiogenic factor production and inhibits cell proliferation and survival in endothelial and tumour cells," Epitheorese Klinikes Farmakologias kai Farmakokinetikes, vol. 18, pp. 30-32, 2004.

[137] D. G. Garcia, L. M. F. Amorim, F. M. V. Castro et al., "The anticancer drug perillyl alcohol is a $\mathrm{Na} / \mathrm{K}$-ATPase inhibitor," Molecular and Cellular Biochemistry, vol. 345, pp. 29-34, 2010.

[138] P. L. Crowell, Z. Ren, S. Lin, E. Vedejs, and M. N. Gould, "Structure-activity relationships among monoterpene inhibitors of protein isoprenylation and cell proliferation," Biochemical Pharmacology, vol. 47, pp. 1405-1415, 1994.

[139] M. B. Sahin, S. M. Perman, G. Jenkins, and S. S. Clark, "Perillyl alcohol selectively induces G0/G1 arrest and apoptosis in Bcr/Abl-transformed myeloid cell lines," Leukemia, vol. 13, pp. 1581-1591, 1999.

[140] Y. Satomi, S. Miyamoto, and M. N. Gould, "Induction of AP-1 activity by perillyl alcohol in breast cancer cells," Carcinogenesis, vol. 20, pp. 1957-1961, 1999.

[141] J. K. Ahn, C. K. Lee, E. K. Choi, R. Griffin, C. W. Song, and H. J. Park, "Cytotoxicity of perillyl alcohol against cancer cells is potentiated by hyperthermia," International Journal of Radiation Oncology, Biology, Physics, vol. 57, pp. 813-819, 2003.

[142] Z. Ren and M. N. Gould, "Inhibition of ubiquinone and cholesterol synthesis by the monoterpene perillyl alcohol," Cancer Letters, vol. 76, pp. 185-190, 1994.

[143] Z. Ren, C. E. Elson, and M. N. Gould, "Inhibition of type I and type II geranylgeranyl-protein transferases by the monoterpene perillyl alcohol in NIH3T3 cells," Biochemical Pharmacology, vol. 54, pp. 113-120, 1997.

[144] I. T. Balassiano, S. A. de Paulo, N. H. Silva et al., "Effects of perillyl alcohol in glial C6 cell line in vitro and anti-metastatic activity in chorioallantoic membrane," International Journal of Molecular Medicine, vol. 10, no. 6, pp. 785-788, 2002.

[145] C. O. Da Fonseca, G. Schwartsmann, J. Fischer et al., "Preliminary results from a phase I/II study of perillyl alcohol intranasal administration in adults with recurrent malignant gliomas," Surgical Neurology, vol. 70, pp. 259-267, 2008.

[146] S. C. Chaudhary, M. S. Alam, M. S. Siddiqui, and M. Athar, "Perillyl alcohol attenuates Ras-ERK signaling to inhibit murine skin inflammation and tumorigenesis," Chemico-Biological Interactions, vol. 179, pp. 145-153, 2009.

[147] E. A. Ariazi, Y. Satomi, M. J. Ellis et al., "Activation of the transforming growth factor $\beta$ signaling pathway and induction of cytostasis and apoptosis in mammary carcinomas treated with the anticancer agent perillyl alcohol," Cancer Research, vol. 59, pp. 1917-1928, 1999.

[148] S. S. Clark, S. M. Perman, M. B. Sahin, G. J. Jenkins, and J. A. Elegbede, "Antileukemia activity of perillyl alcohol (POH): uncoupling apoptosis from G0/G1 arrest suggests that the primary effect of $\mathrm{POH}$ on $\mathrm{Bcr} / \mathrm{Abl}$-transformed cells is to induce growth arrest," Leukemia, vol. 16, pp. 213-222, 2002.

[149] I. V. Lebedeva, Z. Su, N. Vozhilla et al., "Mechanism of in vitro pancreatic cancer cell growth inhibition by melanoma differentiation-associated gene-7/interleukin-24 and perillyl alcohol," Cancer Research, vol. 68, pp. 7439-7447, 2008.

[150] P. J. M. Boon, D. van der Boon, and G. J. Mulder, "Cytotoxicity and biotransformation of the anticancer drug perillyl alcohol in PC12 cells and in the rat," Toxicology and Applied Pharmacology, vol. 167, pp. 55-62, 2000.

[151] L. R. Phillips, L. Malspeis, and J. G. Supko, "Pharmacokinetics of active drug metabolites after oral administration of perillyl alcohol, an investigational antineoplastic agent, to the dog," Drug Metabolism and Disposition, vol. 23, no. 7, pp. 676-680, 1995.

[152] D. Rajesh, R. A. Stenzel, and S. P. Howard, "Perillyl alcohol as a radio-/chemosensitizer in malignant glioma," The Journal of Biological Chemistry, vol. 278, pp. 35968-35978, 2003.

[153] G. H. Ripple, M. N. Gould, J. A. Stewart et al., "Phase I clinical trial of perillyl alcohol administered daily," Clinical Cancer Research, vol. 4, pp. 1159-1164, 1998.

[154] G. H. Ripple, M. N. Gould, R. Z. Arzoomanian et al., "Phase I clinical and pharmacokinetic study of perillyl alcohol administered four times a day," Clinical Cancer Research, vol. 6, pp. 390-396, 2000. 
[155] C. G. Azzoli, V. A. Miller, K. N. G. Kenneth et al., "A phase I trial of perillyl alcohol in patients with advanced solid tumors," Cancer Chemotherapy and Pharmacology, vol. 51, pp. 493-498, 2003.

[156] G. R. Hudes, C. E. Szarka, A. Adams et al., "Phase I pharmacokinetic trial of perillyl alcohol (NSC 641066) in patients with refractory solid malignancies," Clinical Cancer Research, vol. 6, pp. 3071-3080, 2000.

[157] S. M. Meadows, D. Mulkerin, J. Berlin et al., "Phase II trial of perillyl alcohol in patients with metastatic colorectal cancer," International Journal of Gastrointestinal Cancer, vol. 32, no. 23, pp. 125-128, 2002.

[158] W. Wang, N. Li, M. Luo, Y. Zu, and T. Efferth, "Antibacterial activity and anticancer activity of Rosmarinus officinalis L. essential oil compared to that of its main components," Molecules, vol. 17, no. 3, pp. 2704-2713, 2012.

[159] Z. K. Asanova, E. M. Suleimenov, G. A. Atazhanova et al., "Biological activity of 1,8-cineole from levant wormwood," Pharmaceutical Chemistry Journal, vol. 37, pp. 28-30, 2003.

[160] J. Cha, Y. Kim, and J. Kim, "Essential oil and 1, 8-cineole from Artemisia lavandulaefolia induces apoptosis in $\mathrm{KB}$ cells via mitochondrial stress and caspase activation," Food Science and Biotechnology, vol. 19, pp. 185-191, 2010.

[161] A. Calcabrini, A. Stringaro, L. Toccacieli et al., "Terpinen-4ol, the main component of Melaleuca alternifolia (tea tree) oil inhibits the in vitro growth of human melanoma cells," Journal of Investigative Dermatology, vol. 122, pp. 349-360, 2004.

[162] G. Bozzuto, M. Colone, L. Toccacieli, A. Stringaro, and A. Molinari, “Tea tree oil might combat melanoma," Planta Medica, vol. 77, pp. 54-56, 2011.

[163] S. J. Greay, D. J. Ireland, H. T. Kissick et al., "Induction of necrosis and cell cycle arrest in murine cancer cell lines by Melaleuca alternifolia (tea tree) oil and terpinen-4-ol," Cancer Chemotherapy and Pharmacology, vol. 65, pp. 877-888, 2010.

[164] N. K. Dubey, K. Takeya, and H. Itokawa, "Citral: a cytotoxic principle isolated from the essential oil of Cymbopogon citratus against P388 leukemia cells," Current Science, vol. 73, pp. 22-24, 1997.

[165] B. S. Wright, A. Bansal, D. M. Moriarity, S. Takaku, and W. N. Setzer, "Cytotoxic leaf essential oils from neotropical Lauraceae: synergistic effects of essential oil components," Natural Product Communications, vol. 22, pp. 1241-1244, 2007.

[166] Y. Liu, R. J. Whelan, B. R. Pattnaik et al., "Terpenoids from Zingiber officinale (ginger) induce apoptosis in endometrial cancercells through the activation of p53," PLoS ONE, vol. 7, no. 12, Article ID e53178, 2012.

[167] H. Xia, W. Liang, Q. Song, X. Chen, X. Chen, and J. Hong, "The in vitro study of apoptosis in NB4 cell induced by citral," Cytotechnology, vol. 65, pp. 49-57, 2013.

[168] A. Mesa-Arango, J. Monteil-Ramos, B. Zapata, C. Duran, L. Betancur-Galvis, and E. Stashenko, "Citral and carvone chemotypes from the essential oils of Colombian Lippia alba (Mill.) N.E., Brown, composition, cytotoxicity and antifungal activity," Memórias do Instituto Oswaldo Cruz, vol. 104, pp. 878-884, 2009.

[169] E. Aydin, H. Turkez, and M. S. Kele, "Potential anticancer activity of carvone in N2a neuroblastoma cell line," Toxicology and Industrial Health, 2013.

[170] C. Chaverri, C. Diaz, and J. F. Ciccio, "Leaf essential oil of Manekia naranjoana (Piperaceae) from Costa Rica and its cytotoxic activity," Natural Product Communications, vol. 6, pp. 145-148, 2011.
[171] A. Bansal, D. M. Moriarity, S. Takaku, and W. N. Setzer, "Chemical composition and cytotoxic activity of the leaf essential oil of Ocotea tonduziifrom Monteverde, Costa Rica," Natural Product Communications, vol. 2, pp. 781-784, 2007.

[172] D. Fraternale, D. Ricci, C. Calcabrini, M. Guescini, C. Martinelli, and P. Sestili, "Cytotoxic activity of essential oils of aerial parts and ripe fruits of Echinophora spinosa (Apiaceae)," Natural Product Communications, vol. 8, pp. 1645-1649, 2013.

[173] R. A. Cole, A. Bansal, D. M. Moriarity, W. A. Haber, and W. N. Setzer, "Chemical composition and cytotoxic activity of the leaf essential oil of Eugenia zuchowskiae from Monteverde, Costa Rica," Journal of Natural Medicines, vol. 61, pp. 414-417, 2007.

[174] K. Jin, M. Bak, M. Jun, H. Lim, W. Jo, and W. S. Jeong, " $\alpha$-pinene triggers oxidative stress and related signaling pathways in A549 and HepG2 cells," Food Science and Biotechnology, vol. 19, pp. $1325-1332,2010$.

[175] S. Carnesecchi, K. Langley, F. Exinger, F. Gosse, and F. Raul, "Geraniol, a component of plant essential oils, sensitizes human colonic cancer cells to 5-Fluorouracil treatment," Journal of Pharmacology and Experimental Therapeutics, vol. 301, no. 2, pp. 625-630, 2002.

[176] S. Carnesecchi, R. Bras-Goncalves, A. Bradaia et al., "Geraniol, a component of plant essential oils, modulates DNA synthesis and potentiates 5-fluorouracil efficacy on human colon tumor xenografts," Cancer Letters, vol. 215, no. 1, pp. 53-59, 2004.

[177] M. P. Polo and M. G. de Bravo, "Effect of geraniol on fattyacid and mevalonate metabolism in the human hepatoma cell line Hep G2," Biochemistry and Cell Biology, vol. 84, pp. 102-111, 2006.

[178] R. Crespo, S. M. Villegas, M. C. Abba, M. G. de Bravo, and M. P. Polo, "Transcriptional and posttranscriptional inhibition of HMGCR and PC biosynthesis by geraniol in 2 Hep-G2 cell proliferation linked pathways," Biochemistry and Cell Biology, vol. 91, pp. 131-139, 2013.

[179] S. Carnesecchi, Y. Schneider, J. Ceraline et al., "Geraniol, a component of plant essential oils, inhibits growth and polyamine biosynthesis in human colon cancer cells," Journal of Pharmacology and Experimental Therapeutics, vol. 298, pp. 197-200, 2001.

[180] T. P. Ong, R. Heidor, A. de Conti, M. L. Z. Dagli, and F. S. Moreno, "Farnesol and geraniol chemopreventive activities during the initial phases of hepatocarcinogenesis involve similar actions on cell proliferation and DNA damage, but distinct actions on apoptosis, plasma cholesterol and HMGCoA reductase," Carcinogenesis, vol. 27, pp. 1194-1203, 2006.

[181] M. T. Cardozo, A. de Conti, T. P. Ong et al., "Chemopreventive effects of $\beta$-ionone and geraniol during rat hepatocarcinogenesis promotion: distinct actions on cell proliferation, apoptosis, HMGCoA reductase, and RhoA," The Journal of Nutritional Biochemistry, vol. 22, pp. 130-135, 2011.

[182] A. Madankumar, S. Jayakumar, K. Gokuladhas et al., "Geraniol modulates tongue and hepatic phase I and phase II conjugation activities and may contribute directly to the chemopreventive activity against experimental oral carcinogenesis," European Journal of Pharmacology, vol. 705, pp. 148-155, 2013.

[183] L. W. Wattenberg, "Inhibition of azoxymethane-induced neoplasia of the large bowel by 3-hydroxy-3,7,11-trimethyl-1,6,10dodecatriene (nerolidol)," Carcinogenesis, vol. 12, pp. 151-152, 1991. 
[184] J. M. Cherng, D. E. Shieh, W. Chiang, M. Y. Chang, and L. C. Chiang, "Chemopreventive effects of minor dietary constituents in common foods on human cancer cells," Bioscience, Biotechnology, and Biochemistry, vol. 71, pp. 1500-1504, 2007.

[185] L. C. Chiang, W. Chiang, M. Y. Chang, L. T. Ng, and C. C. Lin, "Antileukemic activity of selected natural products in Taiwan," American Journal of Chinese Medicine, vol. 31, pp. 37-46, 2003.

[186] M. R. Loizzo, R. Tundis, F. Menichini, A. M. Saab, and G. A. Statti, "Antiproliferative effects of essential oils and their major constituents in human renal adenocarcinoma and amelanotic melanoma cells," Cell Proliferation, vol. 41, pp. 1002-1012, 2008.

[187] J. Usta, S. Kreydiyyeh, K. Knio, P. Barnabe, Y. Bou-Moughlabay, and S. Dagher, "Linalool decreases HepG2 viability by inhibiting mitochondrial complexes I and II, increasing reactive oxygen species and decreasing ATP and GSH levels," ChemicoBiological Interactions, vol. 180, pp. 39-46, 2009.

[188] Y. Gu, Z. Tinga, X. Qiua et al., "Linalool preferentially induces robust apoptosis of a variety of leukemia cells via upregulating p53 and cyclin-dependent kinase inhibitors," Toxicology, vol. 268, pp. 19-24, 2010.

[189] R. Ravizza, M. B. Gariboldi, R. Molteni, and E. Monti, "Linalool, a plant-derived monoterpene alcohol, reverses doxorubicin resistance in human breast adenocarcinoma cells," Oncology Reports, vol. 20, pp. 625-630, 2008.

[190] H. Maeda, M. Yamazaki, and Y. K. Katagata, "Kuromoji (Lindera umbellata) essential oil-induced apoptosis and differentiation in human leukemia HL-60 cells," Experimental and Therapeutic Medicine, vol. 3, no. 1, pp. 49-52, 2012.

[191] M. Miyashita and Y. Sadzuka, "Effect of linalool as a component of Humulus lupulus on doxorubicin-induced antitumor activity," Food and Chemical Toxicology, vol. 53, pp. 174-179, 2013.

[192] S. Afoulous, H. Ferhout, E. G. Raoelison et al., "Helichrysum gymnocephalum essential oil: chemical composition and cytotoxic, antimalarial and antioxidant activities, attribution of the activity origin by correlations," Molecules, vol. 16, pp. 8273-8291, 2011.

[193] C. C. Woo, S. Y. Loo, V. Gee et al., "Anticancer activity of thymoquinone in breast cancer cells: possible involvement of PPAR- $\gamma$ pathway," Biochemical Pharmacology, vol. 82, no. 5, pp. 464-475, 2011. 

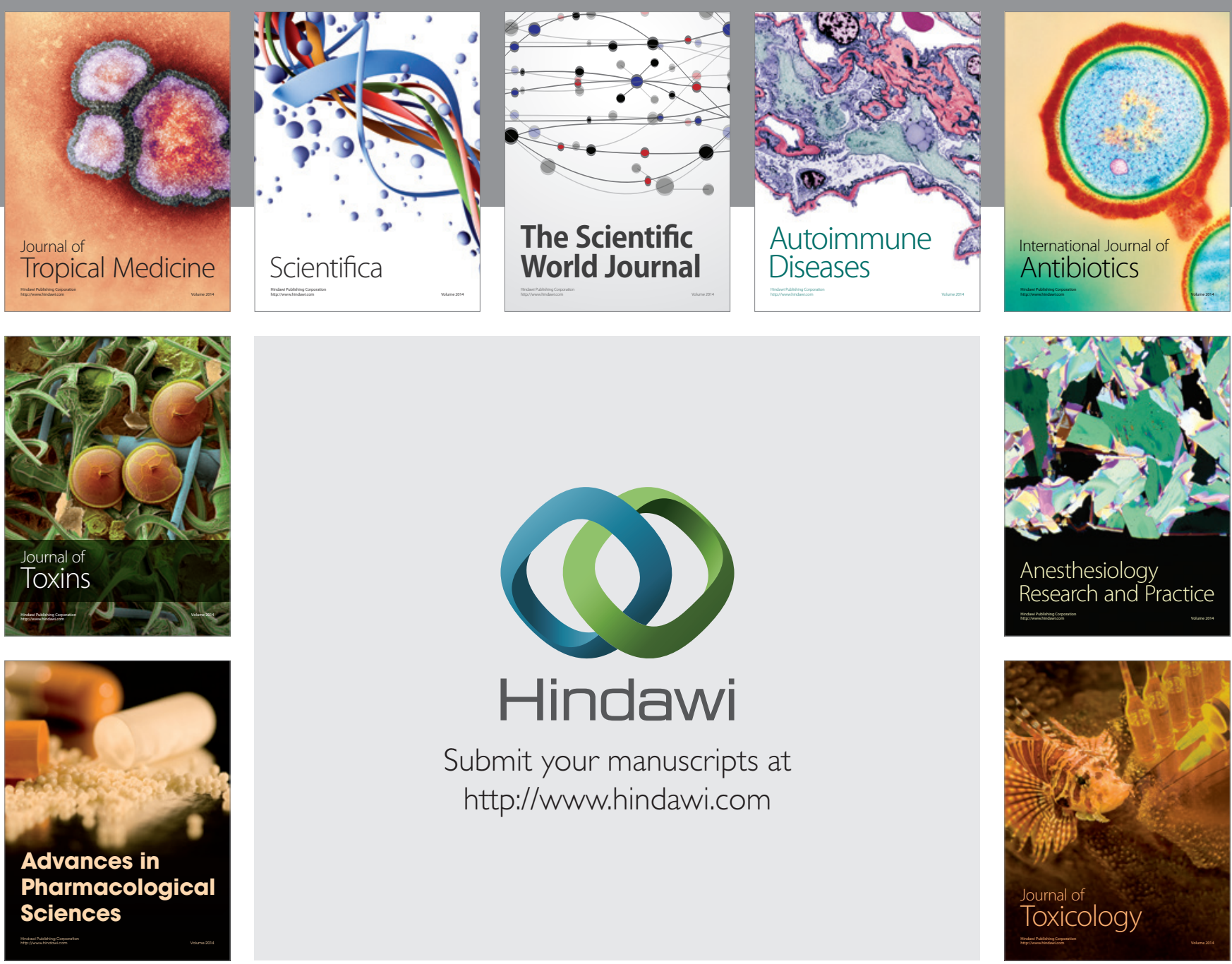

\section{Hindawi}

Submit your manuscripts at

http://www.hindawi.com
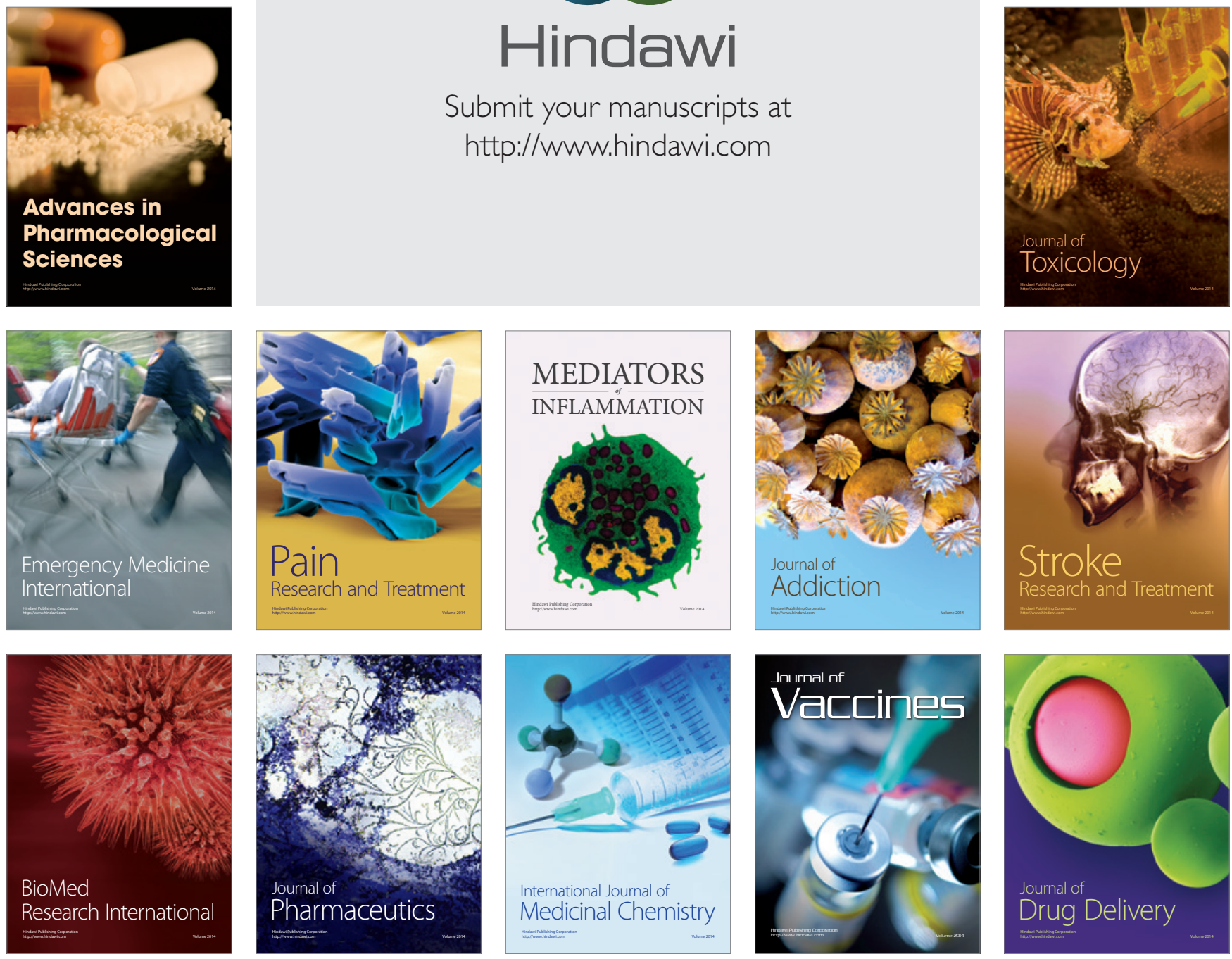